\title{
CFD Modeling of the Multipurpose Hydrogen Test Bed (MHTB) Self-Pressurization and Spray Bar Mixing Experiments in Normal Gravity: Effect of the Accommodation Coefficient on the Tank Pressure
}

\author{
O. Kartuzova and M. Kassemi \\ National Center for Space Exploration Research (NCSER) at NASA Glenn Research Center
}

Cleveland, $\mathrm{OH} 44135$

\begin{abstract}
A CFD model for simulating the self-pressurization of a large scale liquid hydrogen storage tank is utilized in this paper to model the MHTB self-pressurization experiment. The kinetics-based Schrage equation is used to account for the evaporative and condensing interfacial mass flows in this model. The effect of the accommodation coefficient for calculating the interfacial mass transfer rate on the tank pressure during tank selfpressurization is studied. The values of the accommodation coefficient which were considered in this study vary from 1.0e-3 to 1.0e-1 for the explicit VOF model and from 1.0e-4 to 1.0e-3 for the implicit VOF model. The ullage pressure evolutions are compared against experimental data. A CFD model for controlling pressure in cryogenic storage tanks by spraying cold liquid into the ullage is also presented. The Euler-Lagrange approach is utilized for tracking the spray droplets and for modeling the interaction between the droplets and the continuous phase (ul lage). The spray model is coupled with the VOF model by performing particle tracking in the ul lage, removing particles from the ullage when they reach the interface, and then adding their contributions to the liquid. Droplet-ullage heat and mass transfer are modeled. The flow, temperature, and interfacial mass flux, as well as droplets trajectories, size distribution and temperatures predicted by the model are presented. The ullage pressure and vapor temperature evolutions are compared with experimental data obtained from the MHTB spray bar mixing experiment. The effect of the accommodation coefficient for calculating the interfacial and droplet mass transfer rates on the tank pressure during mixing of the vapor using spray is studied. The values used for the accommodation coefficient at the interface vary from 1.0e-5 to 1.0e-2. The droplet accommodation coefficient values vary from 2.0e-6 to 1.0e-4.
\end{abstract}
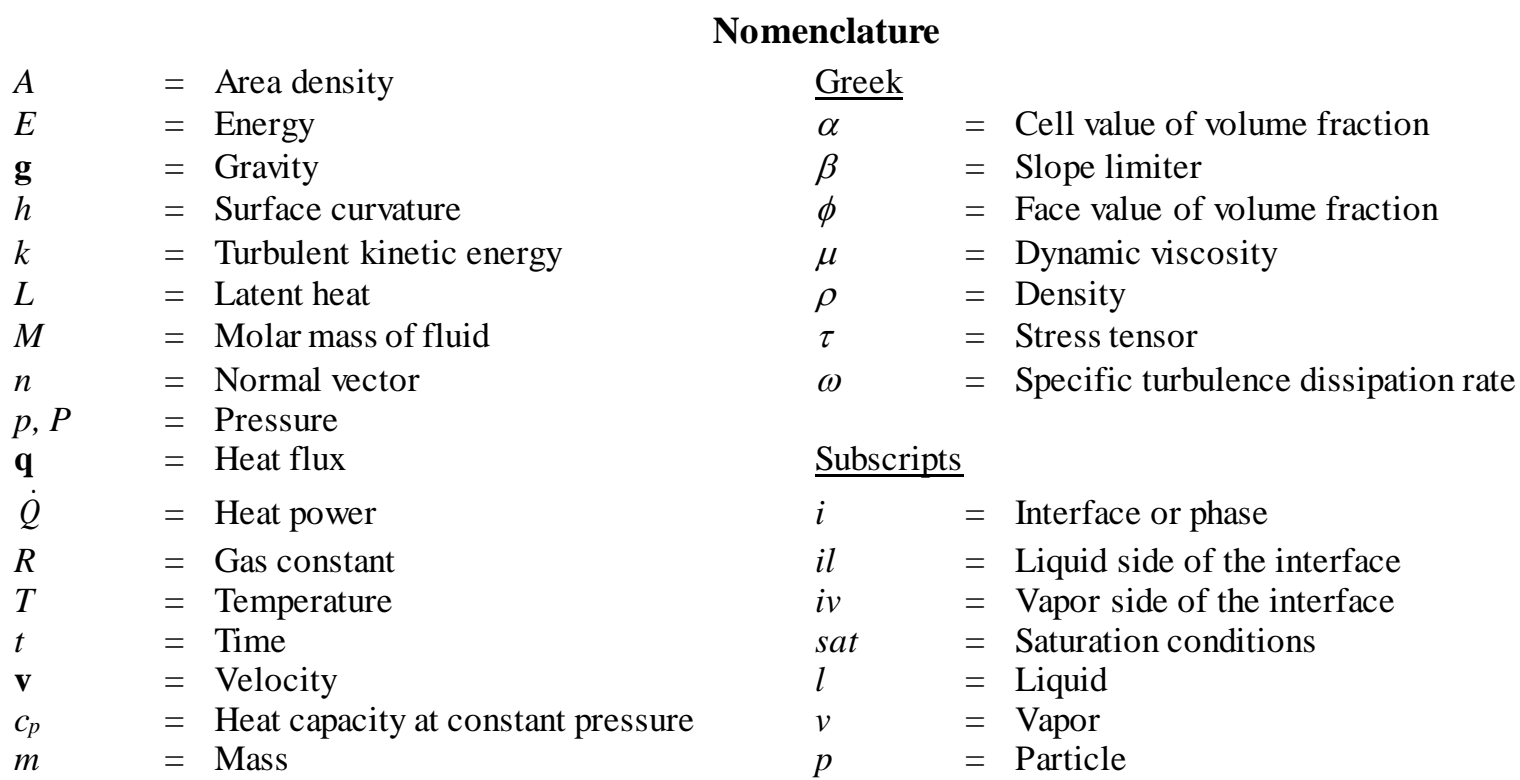

$\begin{array}{ll}\text { Subscripts } & \\ i & =\text { Interface or phase } \\ i l & =\text { Liquid side of the interface } \\ i v & =\text { Vapor side of the interface } \\ s a t & =\text { Saturation conditions } \\ l & =\text { Liquid } \\ v & =\text { Vapor } \\ p & =\text { Particle }\end{array}$

1

American Institute of Aeronautics and Astronautics 


\section{Introduction}

It is crucial for nearly all of the NASA future human exploration mission scenarios to implement efficient cryogenic fluid management of high energy propellants ${ }^{1}$. The main challenges for long duration storage of cryogens in space are the heat leaks through the insulation and various conduction paths that cause tank self-pressurization. Thrusters have traditionally been used to settle the propellant and relieve the tank pressure by venting during short term operations. For long duration missions the added propellant and hardware weight to accommodate the increasing number of venting cycles will be quite prohibitive. Thus, maintaining the tank pressure while minimizing the boil-off loss of propellants through an active pressure control mechanism has become a significant challenge associated with long term storage of cryogens in microgravity ${ }^{2}$.

Among various pressure control strategies that have been proposed and tested, the spray-bar thermodynamic vent system (TVS) has emerged as a promising mechanism that enables tank pressure control through venting without resettling. The key components of a TVS include a Joule-Thomson (J-T) expansion, a twophase heat exchanger, and a spray-bar mixing pump system which enable thermal destratification and the extraction of heat from the tank with minimized liquid cryogen losses ${ }^{3}$ during pressure control. While the further optimization of this pressure control system is possible and demonstration of spray-bar TVS under unsettled conditions is needed, the development of numerical models validated against ground-based test data provides a method to extrapolate and optimize the ground-tested spray-bar TVS design for successful microgravity operations. Development and validation of such numerical tools also supports one of the objectives of the NASA Evolvable Cryogenics project to provide analysis tools for cryogenic fluid management applicable under settled and unsettled conditions.

Numerous numerical models with different degrees of sophistication have been developed to study storage tank operations in $1 \mathrm{~g}$ and/or microgravity ${ }^{4}$. However, many of these models have only studied tank selfpressurization $^{5-7}$. Several have investigated tank pressure control, but mainly for applications where an axial forced jet is used to perform thermal destratification through liquid mixing ${ }^{8-11}$. In MHTB, storage tank pressure control is accomplished through the action of the longitudinal spray-bar Thermodynamic Vent System (TVS) which provides simultaneous mixing and cooling in the liquid and droplet spraying in the ullage region. Comprehensive models of gas-droplet interaction have been developed for thermal management of electronic equipment, evaporative mist flow heat exchangers ${ }^{12}$, and combustion engines ${ }^{13-16}$. However, applications of such models to cryogenic storage tanks have been quite scarce and are limited to lumped models developed by NASA Marshall ${ }^{3}$ and Rockwell Aerospace ${ }^{17}$ and a Flow3D CFD model developed through a NASA-Boeing collaboration ${ }^{18}$. The latter predicted the experimental pressurization and pressure reduction trends well, but with an average $26 \%$ under-prediction of the experimental pressure rise and a 50\% under-prediction of the experimental pressure drop rates.

The results and validation of a comprehensive two-phase CFD model developed by the authors ${ }^{20}$ for simulating the pressurization and pressure control experiments conducted in the Multipurpose Hydrogen Test Bed (MHTB) at the NASA Marshall Space Flight Center (MSFC) will be presented in this paper. The $18-\mathrm{m}^{3}\left(693 \mathrm{ft}^{3}\right)$ storage tank employed in MHTB is representative in both size and shape of a fully integrated space transportation vehicle liquid hydrogen (LH2) propellant tank. The tank was designed to accommodate various components associated with different CFM concepts including a spray-bar TVS system ${ }^{3}$ for active pressure control and a multilayer Insulation (MLI) system for passive thermal isolation ${ }^{2}$.

In the two-phase CFD model of the MHTB test tank presented in this paper, the Volume-of-Fluid (VOF) technique is used to capture the shape and evolution of the interface. A kinetic-based mass transfer submodel is employed to evaluate the evaporative-condensing interfacial mass transfer. In this type of model an accommodation coefficient is used to represent an evaporation or condensation ratio at the interface. The value of the accommodation coefficient can vary between 0 and 1 . The values of the accommodation coefficient for a water-air interface have been extensively studied in the literature. A comprehensive review of research on the water accommodation coefficient is presented by Marek and Straub ${ }^{21}$. However, there is very little information in the literature on the values of the accommodation coefficient for hydrogen. An effect of the accommodation coefficient for calculating the interfacial mass transfer rate on the tank pressure rise during tank self-pressurization is analyzed in this study.

An Euler-Lagrange approach is utilized in this study to track the spray droplets and capture the interaction between the droplets and the continuous phase (vapor). By coupling the droplet and VOF models, it is possible to perform particle tracking in the vapor, removing particles from the vapor domain when they reach the interface and then adding their contributions to the liquid. To account for changes in the tank pressure during the spraying cycle, an in-house droplet-ullage heat and mass transfer model is also developed ${ }^{20}$. The kinetic-based Schrage equation is used to calculate the evaporative/condensing mass transfer from/to the droplet. The droplet temperature and size changes are calculated and tracked during the simulations and appropriate source terms are included in the 
governing equations to account for droplet-ullage mass, momentum, and energy transfer due to phase change. A study of the effect of the accommodation coefficient for calculating the interfacial and droplet mass transfer rates on the tank pressure during mixing via spray is presented in this paper.

In what follows, the important aspects of the mathematical model will be described first, and then the flow, temperature, and interfacial mass flux predicted by the model will be presented. Case studies are performed for the $50 \%$ liquid fill level and the predicted ullage pressure and temperatures are compared against their experimental MHTB counterparts for model validation. The effect of the accommodation coefficient for calculating the interfacial and droplet mass transfer rates on the tank pressure during the self-pressurization and pressure control periods is analyzed.

\section{Mathematical Model}

\section{A. Governing Equations}

The geometry and computational grid for the MHTB cryogenic storage tank partially filled with liquid hydrogen are shown in Fig. 1. This is a 2D axisymmetric grid that was used in the tank self-pressurization study. A $50 \%$ tank fill ratio was considered. A 3D $90^{\circ}$ sector grid, which was created from the $2 \mathrm{D}$ grid by revolving it along the tank centerline, is used to simulate spray cooling of the MHTB tank, and shown in Fig. 4. Fluid flow and heat transfer in the tank are described in terms of the continuity, Navier-Stokes and energy equations for both phases:

$$
\begin{gathered}
\frac{\partial \rho}{\partial t}+\nabla(\rho \mathbf{v})=0, \\
\frac{\partial}{\partial t}(\rho \mathbf{v})+\nabla(\rho \mathbf{v v})=-\nabla p+\nabla\left[\mu_{e f f}\left(\nabla \mathbf{v}+\nabla v^{T}\right)\right]+\rho \mathbf{g}+\mathbf{F}_{v o l}, \\
\frac{\partial}{\partial t}(\rho E)+\nabla(\mathbf{v}(\rho E+p))=\nabla\left(k_{e f f} \nabla T\right)+S_{h} .
\end{gathered}
$$

In the present study, the liquid phase is treated as incompressible with variable temperature-dependent properties, except for the density. The liquid density is allowed to vary linearly with temperature in the body force term of the momentum equation according to the Boussinesq approximation. The vapor is modeled as a compressible ideal gas. All the thermophysical and thermodynamic properties of the fluids are taken from the NIST Chemistry WebBook ${ }^{22}$ at saturation conditions.

In this study, the movement of the interface is captured diffusely using the Volume of Fluid (VOF) method, as promulgated by Hirt and Nichols ${ }^{23}$. Interfacial energy, momentum and mass balances are applied using source terms in the diffuse interfacial region.

\section{B. VOF Model}

In the VOF method, a volume fraction is defined in each cell such that the volume fractions of all the phases sum to unity. In the cell, the change in the interface can be tracked by solving a continuity equation for the volume fraction of the $q^{\text {th }}$ phase:

where the volume fraction for the primary phase is determined from:

$$
\frac{1}{\rho_{q}}\left[\frac{\partial}{\partial t}\left(\alpha_{q} \rho_{q}\right)+\nabla \cdot\left(\alpha_{q} \rho_{q} \mathbf{v}_{q}\right)=S_{\alpha_{q}}\right],
$$

$$
\sum_{q=1}^{n} \alpha_{q}=1
$$

In the VOF method, the field variables and properties are defined in terms of the volume fraction, which for a general system can be written as:

$$
\rho=\sum_{q=1}^{n} \alpha_{q} \rho_{q}, \quad \mu_{e f f}=\sum_{q=1}^{n} \alpha_{q} \mu_{e f f_{q^{\prime}}} \quad k_{e f f}=\sum_{q=1}^{n} \alpha_{q} k_{e f f_{q}} .
$$

In this fashion, the continuity, momentum and energy equations, as described by Eq. (1) - (3), can be solved throughout the domain for the temperatures and velocities in the two phases. In the VOF model, energy $(E)$ and temperature $(T)$ are treated as mass-averaged variables:

$$
E=\frac{\sum_{q=1}^{n} \alpha_{q} \rho_{q} E_{q}}{\sum_{q=1}^{n} \alpha_{q} \rho_{q}}
$$

where $E_{q}$ is based on the specific heat of the $q^{\text {th }}$ phase and the shared temperature. 
Evaporation and condensation at the interface are modeled as a source term in the continuity equation for the volume fraction (Eq. 4), i.e.:

$$
S_{\alpha_{q}}=\dot{\mathbf{m}}_{i} \cdot \mathbf{A}_{i}
$$

where $\mathbf{A}_{i}$ is an interfacial area density vector, and $\dot{\mathbf{m}}_{i}$ is a mass flux vector, which for near equilibrium conditions can be determined based on the $\mathrm{Schrage}^{24}$ equation:

$$
|\dot{\mathbf{m}}|=\left(\frac{2 \sigma}{2-\sigma}\right)\left(\frac{M}{2 \pi R}\right)^{1 / 2}\left(\frac{P_{i}}{T_{i}^{1 / 2}}-\frac{P_{v}}{T_{v}^{1 / 2}}\right) .
$$

Here $\sigma$ is the accommodation coefficient; $M$ is the molar mass of the fluid; $R$ is the universal gas constant; $P_{i}$ and $P_{v}$ are, respectively, the interfacial and vapor pressures (it was assumed that $P_{i} \cong P_{s a t}$ ); $T_{i}$ and $T_{v}$ are, respectively, the interfacial and vapor temperatures (it was assumed that $T_{i}=T_{v} \cong T_{\text {sat }}$ at the interface). Finally, $\mathbf{A}_{\mathbf{i}}$ is defined as:

where $\alpha$ is the volume fraction of the primary phase.

$$
\mathbf{A}_{i}=|\nabla \alpha|,
$$

In the present implementation, the surface tension forces at the interface are modeled via the Continuum Surface Force (CSF) model of Brackbill et al. ${ }^{25}$. In this model, the surface tension forces at the interface are transformed into a volume force $\left(\mathbf{F}_{v o l}\right)$, which is added as a source to the momentum equation:

$$
\mathbf{F}_{\text {vol }}=\sum_{\text {pairs } i j, i<j} \sigma_{i j} \frac{\alpha_{i} \rho_{i} h_{i} \nabla \alpha_{j}+\alpha_{j} \rho_{j} h_{j} \nabla \alpha_{i}}{\frac{1}{2}\left(\rho_{i}+\rho_{j}\right)},
$$

where $h_{i}$ is the surface curvature calculated from the local gradients in the surface normal at the interface:

$$
h_{i}=\nabla \cdot \widehat{\mathbf{n}} \text {. }
$$

\section{Turbul ence modeling}

In this study, the tank turbulence was modeled by utilizing the Shear Stress Transport $k-\omega$ model of Menter ${ }^{19}$. This model is similar to the standard $k$ - $\omega$ model of Wilcox ${ }^{26}$, but has the ability to account for the transport of the principal shear stress in adverse pressure gradient boundary layers. The model is based on the assumption of Bradshaw et al. ${ }^{27}$ that the principal shear stress is proportional to the turbulent kinetic energy, which is introduced into the definition of the eddy-viscosity. These features make the kw-SST model more accurate and reliable for a wider class of flows than the standard $k-\omega$ model $^{28}$.

In the VOF model, continuity of the turbulent quantities is inherently assumed since one set of equations for the turbulent kinetic energy and dissipation rate is solved for both phases throughout the domain, with properties varying according to the local volume fraction value.

\section{Lagrangian Spray model}

A customized Lagrangian Spray model of the ANSYS Fluent CFD code was utilized for simulating the cooling of the MHTB tank by spraying cold liquid in a vapor region. This model uses the Euler-Lagrange approach, where the fluid phase (ullage) is treated as a continuum by solving the Navier-Stokes equations. The dispersed phase is solved by tracking a large number of particles (spray droplets) through the calculated flow field. The droplets exchange mass, momentum and energy with the fluid phase. In the Lagrangian spray model, the droplet trajectory is calculated by integrating the force balance on the droplet. This force balance equates the droplet inertia with the forces acting on the droplet as:

$$
\frac{d \vec{u}_{p}}{d t}=F_{D}\left(\vec{u}-\vec{u}_{p}\right)+\frac{\vec{g}\left(\rho_{p}-\rho\right)}{\rho_{p}}+\vec{F}
$$

where $\vec{u}$ is the fluid phase velocity, $\vec{u}_{p}$ is the particle velocity, $\rho$ is the fluid density, $\rho_{p}$ is the density of the droplet, $F_{D}$ is the drag force per unit droplet mass, and $\vec{F}$ is an additional acceleration. Integration of time in equation 13 yields the velocity of the droplet at each point along the droplet trajectory.

The spherical drag law proposed by Morsi and Alexander ${ }^{29}$ is applied for the droplet drag force calculation.

The droplet energy equation is solved in the user subroutine as:

$$
m_{p} c_{p_{p}} \frac{d T_{p}}{d t}=h \cdot A_{p}\left(T_{\infty}-T_{p}\right)-L \dot{m}_{p},
$$


where $m_{p}$ is the droplet mass, $c_{p_{p}}$ is the heat capacity of the droplet, $A_{p}$ is the surface area of the droplet, $T_{\infty}$ is the local temperature of the continuous phase, $h$ is the convective heat transfer coefficient, $L$ is the latent heat, and $\dot{m}_{p}$ is the rate of evaporation/condensation on the droplet, obtained from the Schrage relation (equation 9) in $\mathrm{kg} / \mathrm{s}$.

The temperature of the droplet is obtained from equation 14 using the correlation of Ranz and Marshall ${ }^{30,31}$ for evaluating the heat transfer coefficient:

$$
N u=\frac{h d_{p}}{k_{\infty}}=2.0+0.6 \operatorname{Re}_{d}^{1 / 2} \operatorname{Pr}^{1 / 3}
$$

where $d_{p}$ is the droplet diameter, $k_{\infty}$ is the thermal conductivity of the continuous phase, $R e_{d}$ is the Reynolds number based on the particle diameter and the relative velocity, and $\operatorname{Pr}$ is the Prandtl number of the continuous phase.

The relative Reynolds number is calculated as:

$$
R e_{d} \equiv \frac{\rho d_{p}\left|\overrightarrow{u_{p}}-\vec{u}\right|}{\mu}
$$

where $\mu$ is the molecular viscosity of the fluid.

After the droplet energy equation is solved in the user subroutine, the mass, diameter and temperature of the droplets are updated. The mass, momentum and energy transfer between the droplets and continuous phase is modeled via source terms added to equations 1-3.

The Lagrangian Spray model is coupled with the VOF model via a user subroutine which performs particle tracking in the ullage, removes particles from the ullage when they reach the interface, and then adds their contributions to the liquid mass, momentum and energy equations through source terms (for those liquid cells near the location where the spray drops crossed the liquid-vapor interface). Because the VOF method produces a diffuse interface, the criteria for determining when the spray drops have crossed into the bulk liquid was defined as the liquid drop entering a fluid cell with a liquid volume fraction $>0.1$.

\section{Numerical Implementation}

The interfacial mass transfer formulation used with the VOF scheme, the droplet/ullage heat and mass transfer, and the coupling between the VOF and Lagrangian Spray models have been developed, coded, and implemented into a customized in-house version of the ANSYS Fluent version 16.0 CFD code. In the VOF model, the interfacial mass transfer is calculated in the user subroutine, and sources are applied to the momentum and relevant scalar equations based on the assumption that mass "created" or "destroyed" will have the same momentum and energy of the phase from which it was "created" or "destroyed" 28 . All of the two-phase calculations are performed in the user subroutine, which is called once per outer iteration before any of the field equations are solved.

In the tank self-pressurization cases, the computational domain was discretized using an unstructured mesh of 9,246 cells, as depicted in Fig. 1. In both the ullage and liquid regions, the conservation equations are evolved in time using a bounded second order time stepping routine with a time step size on the order of $1 \times 10^{-2}$ seconds for self-pressurization cases with the implicit VOF model and $1 \times 10^{-3}$ with the explicit VOF model. A lower time step size of $3 \times 10^{-4}$ is used with the explicit VOF model with the accommodation coefficient equal to 0.1 , which was the highest value that was tested. A time step size value of $1 \times 10^{-2}$ seconds is used with the implicit VOF model for the spray case. The second order monotone upwinding scheme is used to discretize the convective fluxes in the momentum, energy and turbulence equations. The PISO method is used for the pressure-velocity coupling.

For the volume fraction equation, the Compressive discretization scheme is used. The Compressive scheme is a second order reconstruction scheme for the VOF equation based on the slope limiter ${ }^{28}$. In this scheme:

$$
\phi_{f}=\phi_{d}+\beta \nabla \alpha_{d}
$$

where $\phi_{f}$ is the face value of the volume fraction, $\phi_{d}$ is the donor cell value of the volume fraction, $\beta$ is the slope limiter, and $\nabla \alpha_{d}$ is the donor cell volume fraction gradient.

In the Lagrangian spray cases, cold liquid enters the liquid phase as a "tiny jet" which is modeled as a source term defined in a user subroutine; which is added to the mass, energy and momentum equations in Fluent. Pressure control using the spray bar TVS is simulated for the 50\% liquid fill ratio case. The results for the pressure control period for the $90 \%$ liquid fill ratio case were presented by the authors earlier ${ }^{20}$. In the $50 \%$ fill ratio case there are 22 liquid jets in the liquid region, and 21 spray injections in the vapor region. Both the liquid jets and the spray injections have the same uniform temperature of $21.088 \mathrm{~K}$ and a variable liquid flow rate ranging from 0 to $7.5447 \mathrm{e}-4 \mathrm{~kg} / \mathrm{s}$. The spray injection type is a plain orifice atomizer with four particle streams per injection. Two-way

American Institute of Aeronautics and Astronautics 
coupling between the droplets and the continuous phase is enabled. In order to model heat and mass transfer between the droplets and the ullage, first a value for the mass transfer rate is calculated in the subroutine. Then the droplet energy equation is solved, and the droplet temperature is updated. The mass and diameter of the droplet are updated to account for the amount of the evaporated or condensed mass. Then, corresponding mass and energy sources are added to the ullage. $1 \times 10^{-8}$

Convergence criteria are set to $1 \times 10^{-5}$ for all equations except the energy equation, for which it is set to

\section{Results and Discussion}

The computational cases presented in this paper are based on the MHTB tank self-pressurization and spray bar mixing experiments (Test Segment P263981T) conducted in normal gravity ${ }^{3}$. The MHTB tank consists of a cylindrical mid-section with a $3.05 \mathrm{~m}$ diameter and $3.05 \mathrm{~m}$ height and two 2:1 elliptical end caps. The experiment was conducted with three different tank liquid fill ratios (25\%,50\% and $90 \%)$. The CFD results for the $90 \%$ tank fill ratio were presented by the authors earlier ${ }^{20}$. The results of the simulations for the $50 \%$ tank liquid fill ratio are examined in detail in this paper. First, the effect of the accommodation coefficient for calculating the interfacial mass transfer rate on the tank pressure during tank self-pressurization is discussed. Second, the results of the spray bar mixing simulations are presented and the effect of the accommodation coefficient for calculating the interfacial and droplet mass transfer rates on the tank pressure is analyzed. Only the first spray on/off cycle after selfpressurization in Test Segment P263981T is simulated during which no liquid is directed into the Joule Thomson device, and thus the temperature of the liquid exiting the spray bar is essentially the same as the temperature of the liquid entering into the pump located near the tank bottom.

The gravitational vector is aligned with the tank's central axis in the negative axial direction. A uniform heat flux of $0.89873 \mathrm{~W} / \mathrm{m}^{2}$ was applied at the inside of the tank wall in the vapor region, and $2.0841 \mathrm{~W} / \mathrm{m}^{2}$ in the liquid region. These values are based on previous thermal analysis and multi-node simulations. Conduction through the tank wall was not considered. The spray bar assembly is approximated as lying along the tank centerline. Its wall is treated as an adiabatic surface.

A zero velocity field and the experimental tank temperature profile were applied as initial conditions for the tank self-pressurization simulations. The details of the self-pressurization cases are presented in Table 1 . All of the tank self-pressurization cases were run as laminar (no turbulence model was applied). The effect of turbulence modeling during tank self-pressurization was studied by the authors earlier ${ }^{20}$. Tank self-pressurization was modeled using a $2 \mathrm{D}$ axisymmetric formulation. The temperature and velocity fields at the end of tank self-pressurization were interpolated into a $3 \mathrm{D} 90^{\circ}$ sector grid and were used as initial conditions for spray-bar mixing simulations. Laminar and turbulent approaches were compared for modeling spray-bar mixing in the MHTB tank. In the turbulent case, the Shear Stress Transport $k-\omega$ model of Menter ${ }^{19}$ was used. Uniform values were used for the turbulent kinetic energy $\left(k=1 \times 10^{-6}, \mathrm{~m}^{2} / \mathrm{s}^{2}\right)$ and specific dissipation rate $(\omega=100,1 / \mathrm{s})$ as initial conditions. The details of the spraybar mixing case are presented in Table 2. The initial tank pressure matched the experimental one for each case as given in Tables 1 and 2.

Table 1: Experimental conditions for tank self-pressurization test

\begin{tabular}{cccc}
\hline Initial liquid fill, \% & Initial pressure, $\boldsymbol{k P a}$ & Final Pressure, $\boldsymbol{k P a}$ & Test Duration, hours \\
\hline 50 & 111.6 & 137.9 & 13.9 \\
\hline
\end{tabular}

Table 2: Experimental conditions for spray-bar mixing test

\begin{tabular}{cccc}
\hline Initial liquid fill, \% & Initial pressure, $\boldsymbol{k P a}$ & Final Pressure, $\boldsymbol{k P a}$ & Test Duration, $\boldsymbol{s}$ \\
\hline 50 & 137.9 & 131.0 & 40 \\
\hline
\end{tabular}

A grid independence study was performed by the authors for the 50\% fill ratio self-pressurization case and presented earlier ${ }^{20}$. The self-pressurization simulation required about 10 hours using 8 AMD Opteron ${ }^{\mathrm{TM}} 6100$ Series ("Magny-Cours") processors to complete 5000 seconds of self-pressurization. The computational 2D axisymmetric grid used for the tank self-pressurization simulations is shown in Fig. 1. This grid is refined near the interface and tank walls.

A study of the effect of the accommodation coefficient for calculating interfacial mass transfer rate on the tank pressure during tank self-pressurization was performed using the implicit and explicit VOF models. The tank pressure and interfacial mass transfer rate evolutions from the implicit VOF model with two different values of the 
interfacial mass transfer rate accommodation coefficient, 1.0e-3 and 1.0e-4, are compared in Fig. 2. The experimental tank pressure is also plotted in Fig. 2, but no experimental data on the interfacial mass transfer rate was available for comparison. The tank pressures predicted by the implicit VOF model with both of the values of the accommodation coefficient that were tested are in excellent agreement with the experimental ones. This model predicts evaporation (positive values of the mass transfer rate) at the interface for the first 1000 seconds of the tank self-pressurization period. It predicts condensation at the interface for the rest of the simulation time. The results of the implicit VOF model, with the accommodation coefficient set to $1.0 \mathrm{e}-3$ and $1.0 \mathrm{e}-4$, are very similar to each other for both the tank pressure and interfacial mass transfer rate. Higher values for the accommodation coefficient when used with the implicit VOF model, result in the solution becoming unstable and diverging. Three different values of the accommodation coefficient were tested with the explicit VOF model. The values ranged from $1.0 \mathrm{e}-3$ and $1.0 \mathrm{e}-1$. The tank pressures predicted by the implicit VOF model with four different values of the accommodation coefficient used to calculate the interfacial mass transfer rate are compared in Fig. 3 with experimental data. The CFD predictions for the interfacial mass transfer rate are plotted in Fig. 3, as well, however, no experimental data on the interfacial mass transfer rate was available for comparison. The explicit VOF model results are very similar to the results of the implicit VOF model (compare Fig. 2b and Fig. 3), however, the explicit VOF model requires a smaller time step size and, therefore, a longer computational time. The effect of the value of the accommodation coefficient on the predicted interfacial mass transfer rate is more pronounced with the explicit VOF model. The explicit VOF model with higher values of the accommodation coefficient produces larger amounts of evaporation at the interface for the first 200 seconds of tank self-pressurization, which does not significantly affect the tank pressure rise. After 200 seconds of the tank self-pressurization the interfacial mass transfer rate predicted by this model is no longer significantly affected by the value of the accommodation coefficient.

A 3D $90^{\circ}$ sector grid used for spray-bar mixing simulations is shown in Fig. 4a. It is created from the 2D axisymmetric grid by revolving it along the tank centerline. It has 20 nodes in the azimuthal direction. The grid is refined near the interface, tank wall and spray-bar wall. A schematic of the tank with the spray-bar holes and pump locations is shown in Fig. 4b. There are 22 holes in the liquid region, which are modeled as liquid jet point sources for mass, momentum and energy and 21 holes in the vapor region, which are modeled as spray injections using the plain orifice atomizer model with four particle streams per injection. Area averaged sink terms are added for mass, momentum and energy at the pump location to account for liquid recirculating in the TVS system. Liquid hydrogen is injected into the vapor with constant properties at $\mathrm{T}=21.088 \mathrm{~K}$. The spray-bar hole diameter is $1.7 \mathrm{e}-03 \mathrm{~m}$ with a flow-through length of $0.711 \mathrm{e}-03 \mathrm{~m}$. The total liquid flow rate into the spray-bar assembly is based on measured flow rate data ${ }^{3}$ and does vary with time. In the simulations, the liquid flow rate is distributed uniformly to all spray-bar holes (43 holes in each of the four spray-bar tubes). A summary of the droplets coming out of the spray bar holes after 1 time step $(0.01 \mathrm{~s})$ is shown in Table 3.

Table 3: Droplets summary after 1 time step

\begin{tabular}{lc}
\hline Number of injections & 21 \\
\hline Injector inner diameter & $1.70 \mathrm{e}-03 \mathrm{~m}$ \\
\hline Total number of parcels & 84 \\
\hline Total number of droplets & 2880 \\
\hline Total mass of droplets & $1.20 \mathrm{e}-04 \mathrm{~kg}$ \\
\hline Maximum droplet diameter & $1.46 \mathrm{e}-03 \mathrm{~m}$ \\
\hline Minimum droplet diameter & $8.06 \mathrm{e}-04 \mathrm{~m}$ \\
\hline Overall mean diameter & $1.00 \mathrm{e}-03 \mathrm{~m}$ \\
\hline
\end{tabular}

The tank pressure evolutions from spray-bar mixing simulations are compared with experimental data in Fig. 5. The predicted interfacial mass transfer rate evolutions are presented in Fig. 5, as well; however, no experimental data was available for comparison. The results of the laminar and turbulent $(k-\omega-S S T)$ VOF models are compared for both the tank pressure and interfacial mass transfer rate. Both models predict very similar tank pressure decreases during spray-bar mixing, which agree with the experimental data very well. Both models predict similar values of evaporation (positive values of mass transfer rate) at the interface during spray-bar mixing. The turbulent VOF model was selected for a detailed analysis of the tank during spray cooling; the results are shown in Fig. 6-13.

Vapor temperature contours at the center plane of the spray bar after 1 second of spraying are shown in Fig. 6 along with the droplets, which are colored by the droplet temperature. Mass transfer rate contours are shown at the 
interface. The droplet and vapor temperature ranges are matched for comparison purposes. The droplets that come out of the spray bar holes are initially colder than the vapor, but as they travel towards the interface, they are heated by the vapor. The droplets that are injected at the top of the tank travel through a region of warmer vapor due to the thermal stratification in the tank that was created during tank self-pressurization. When these droplets approach the interface they are warmer than the colder layer of vapor near the interface. When these droplets reach the interface and are absorbed by the liquid, they increase the interfacial temperature in the areas of high droplet concentration. This results in a local increase in evaporation rate at the interface, as shown in Fig. 6.

Figure 7 shows vapor temperature contours at the center plane of the spray bar holes, and at three different horizontal planes in the vapor after 1 second of spraying. Droplets colored by the droplet temperature and streamlines are also shown in Fig. 7. The droplet and vapor temperature ranges are matched for comparison purposes. It is noticeable that droplets affect the flow in the vapor, moving mixing flow pattern that remained from the self-pressurization period towards the tank wall. As shown in the horizontal planes, the droplets have a very narrow spread in the lateral direction and create recirculation regions on both sides of the injection center plane. These recirculations, promote mixing in the tank during spray cooling. The droplets are much colder than the vapor at the top horizontal plane located in the vapor region. The temperature of the droplets is similar to the vapor temperature in the middle of the vapor region. The droplets are warmer than the vapor at the bottom of the vapor region close to the interface.

Temperature contours in the tank at the center plane of the spray bar holes are shown in Fig. 8 at three different times during spray-bar mixing: 1, 15 and 34 seconds. The figure shows that spray effectively mixes the vapor and lowers the vapor temperature after 34 seconds of mixing. The reduced temperature range, focusing on the portion of the tank filled with liquid, is shown in Fig. 9. The temperature contours are plotted at the center plane of the spray bar holes at three different times during spray-bar mixing: 1,15 and 34 seconds. The interface is shown by the white line at the top of the liquid region. There is a thin layer of warm liquid right below the interface, which is only 0.5 degree warmer than the rest of the liquid. The liquid temperature does not change during the spray-bar mixing period.

Fig. 10 shows droplets colored by temperature at 1,15 and 34 seconds of spray. Cold droplets are entering the tank at the spray bar hole location; they warm up as they travel through the vapor, especially at the center of the vapor region, as shown in Fig. 10. The region covered by warm droplets is largest at 15 seconds of spraying, as compared to the beginning of spraying at 1 second. At 34 seconds of spraying the droplets are significantly cooler because the vapor region is already cooled down and mixed. Figure 11 shows vapor temperatures and streamlines at 1,15 and 34 seconds of spray cooling. Droplets colored by the droplet temperature are shown in Fig. 11, as well. The flow of droplets alters the vapor flow, aligning it with the droplets' trajectory after 15 seconds of mixing. The droplets effectively cool down and mix the vapor region, as can be seen in Fig. 11. A white line in the middle of the vapor region shown in Fig. 11 indicates the horizontal location of the temperature measurement diode TD4. The vapor temperatures at this location at 1, 15 and 34 seconds of spray-bar mixing are shown in Fig. 12. Droplets colored by the droplet temperature are shown in Fig. 12, as well. Fig. 12 indicates that the spray creates a nonuniformity in the vapor temperatures in the lateral direction by the middle of the mixing period (15 seconds). At the very beginning of the mixing period ( 1 second) the vapor temperature is uniform in the lateral direction, while stratification is present in the vertical direction (see Fig. 11). By the end of the mixing period (34 seconds) the vapor is well mixed in both the lateral and vertical directions (see Fig. 11 and 12). Due to the non-uniformity in the vapor temperature in the lateral direction any temperature measurement would depend greatly on the measurement location. The locations of the temperature probes in CFD simulation have to exactly match the experimental setup in order to make a direct comparison between the experiment and the CFD predictions.

The temperature was measured at different locations in the vapor and liquid regions in experiment. The temperatures calculated in CFD were compared with experimental data; however, there are some discrepancies between the CFD and experimental initial conditions and the position of the spray-bar tube relative to the temperature measurement rake. The temperature field from the laminar VOF model at the end of the selfpressurization period was used as an initial condition for spray bar mixing simulations. As shown in Fig. 13, vapor temperatures calculated by this model at the end of the self-pressurization period are higher than the experimental ones. Therefore, there is a difference in the initial conditions between the model and the experiment at the beginning of the spray period. A comparison of the schematic between the experimental and computational spray bars relative to the temperature measurement rake position is shown in Fig. 14. In the experiment, the spray bar assembly is not located at the tank axis. In the CFD model it is moved to the tank centerline to allow $90^{\circ}$ sector of the tank to be modeled, rather than the entire tank, in order to save computational time. This resulted in the positioning of the temperature measurement rake at the center of the plane of the injections in CFD, although in the experiment it is not necessarily in the direction of the spray. All of these conditions make a comparison between the measured and 
computed temperatures in the tank qualitative rather than quantitative. The temperature evolutions at three different measurement locations in the vapor region and one location in the liquid region, calculated by the laminar and turbulent VOF models, are compared with experimental data in Fig. 15-18. Due to the difference in the initial temperatures between the CFD model and the experiment, the results presented in Fig. 15-18 are referenced to their respective temperatures at the beginning of the spray period. The temperature evolutions at the measurement location at the top of the vapor region (TD1) from the laminar and turbulent VOF models are compared with each other and with experimental data in Fig. 15a. At this location, both models predict temperatures that compare well with the experimental data for the first 20 seconds of spray-bar mixing. The temperatures predicted by the laminar VOF model agree with the experimental ones between 20 and 40 seconds of mixing. The turbulent VOF model predicts a faster temperature drop in the vapor than in the experiment after 20 seconds of mixing. Fig. $15 \mathrm{~b}$ shows the vapor and droplets temperature contours near the end of the mixing period (at 34 seconds) from the laminar and turbulent VOF models. Temperature measurement location TD1 is shown in Fig 15b by a black marker. The turbulent VOF model predicts less thermal stratification in the vapor than does the laminar VOF model.

Fig. 16 shows a comparison between the temperature evolutions in the middle of the vapor region (at the temperature measurement location TD4) predicted by the laminar and turbulent VOF models with experimental data. Both models predict a similar slope for the temperature decrease in the vapor, which agrees with the experimental one. However, in the beginning of spray-bar mixing, both models predict a sudden sharp increase in temperature (this is more pronounced in the laminar VOF model results) which is not shown by the experimental data. The temperature measurement location in CFD is located at the center plane of the spray bar holes, as shown in Fig. 14. The location of the temperature rake relative to the spray bar is somewhat different in the experiment, as shown in Fig. 14. The temperature at the same radial position, but at the side of the computational domain is shown in Fig. 15 from the laminar CFD model for comparison. This temperature does not show sudden increases throughout the mixing period, and compares well with the experimental data. Vapor temperature contours near the end of mixing (at 34 seconds) from the laminar and turbulent VOF models are shown in Fig. 16b. Temperature measurement location TD4 is shown in Fig $16 \mathrm{~b}$ by a black marker.

A comparison between the temperature evolutions at the bottom of the vapor region near the interface (at temperature measurement location TD6) from the laminar and turbulent VOF models and experimental data is shown in Fig. 17a. At this location, both models predict a sudden sharp increase in temperature at the center plane of injections in the beginning of mixing, which is not present in the experiment. However, at the same radial position at the side of the computational domain, such a sudden increase is not predicted by the laminar VOF model. Similar behavior is observed in the simulation results at the TD4 location. At the TD6 location the vapor temperature slightly increases during spray-bar mixing in both CFD and the experiment. The computational temperature evolution slope matches the experimental one at this location. Fig. 17b once again shows vapor temperature contours near the end of mixing from the laminar and turbulent VOF model with the TD6 measurement location shown by the white marker.

The temperature evolutions in the liquid (TD7) are compared between the laminar and turbulent VOF models and the experiment in Fig.18a. The liquid temperature remains constant in both the experiment and the CFD predictions. Fig. 18b shows temperature contours in the liquid at 34 seconds of mixing. Both the laminar and turbulent CFD models show similar temperature distributions in the liquid. The TD7 measurement location is shown in Fig. $18 \mathrm{~b}$ by the white marker.

The effect of the accommodation coefficient on the tank pressure decrease during spray-bar mixing was studied and the results are presented in Fig. 19 for the interfacial accommodation coefficient and in Fig. 20 for the droplet one. As shown in Fig. 19, changing the accommodation coefficient at the interface from 1.0e-5 to $1.0 \mathrm{e}-2$ with the droplet accommodation coefficient kept constant at $1.0 \mathrm{e}-05$ had very little effect on the tank pressure predicted in CFD. Fig. 20 shows that changing the droplet accommodation coefficient from $2.0 \mathrm{e}-6$ to $1.0 \mathrm{e}-4$ with a constant value for the accommodation coefficient at the interface of $1.0 \mathrm{e}-3$ has a significant effect on the tank pressure decrease during spray-bar mixing. The smaller the droplet accommodation coefficient, the slower is the pressure decrease in the tank. The CFD model with the droplet accommodation coefficient equal to 2.0e- 6 and an interfacial value of $1.0 \mathrm{e}-3$ produced the best agreement with the experimental data.

The effect of the accommodation coefficient for calculating the interfacial mass transfer rate during tank self-pressurization on the tank pressure rise was studied. Changing the value of the accommodation coefficient from $1.0 \mathrm{e}-4$ to $1.0 \mathrm{e}-3$ had very little effect on the tank pressure when the implicit laminar VOF model was used. Using accommodation coefficient values varying from $1.0 \mathrm{e}-3$ to $1.0 \mathrm{e}-1$ with the explicit VOF model resulted in very similar tank pressure values that agree well with the experimental data. A droplet/ullage heat and mass transfer model was developed and implemented with the Lagrangian spray and the VOF models of ANSYS Fluent commercial CFD code. This model was utilized for simulating the MHTB spray bar mixing experiment. The results 
of the model agree very well with the experimental data for the pressure decrease in the tank during the spray-bar mixing period. The laminar and turbulent VOF models resulted in very similar tank pressures and interfacial mass transfer rates during spray bar mixing in the tank. Both models predicted evaporation at the interface during the entire mixing period. A detailed analysis of the results of the turbulent VOF case shows that the droplets reduce the temperature and promote mixing in the vapor region via heat and mass exchange during the spray period. Droplets warm up as they travel in the vapor towards the interface, and create hot regions in the areas of higher droplet concentration in the middle of the vapor phase. The CFD predicted a very narrow spray angle. There is no information on the spray angle from the experiment to compare with. The temperature evolutions predicted in CFD compare well with the slopes of the temperature evolutions from experiment. Discrepancies in the initial conditions and the position of the spray bar tube relative to the temperature measurement rake between the CFD model and the experiment make the comparison of the temperature values qualitative rather than quantitative. The effect of the accommodation coefficient for calculating the interfacial and droplet mass transfer rates during spray bar mixing in the tank on the tank pressure decrease was studied. Varying the interfacial accommodation coefficient had very little effect on the tank pressure. Changing the droplet accommodation coefficient had a significant effect on the tank pressure, with the value of 2.0e-6 yielding the best comparison with the experiment.

\section{Conclusion}

A two-phase compressible VOF CFD model for self-pressurization and pressure control inside cryogenic storage tanks was developed ${ }^{20}$ and utilized for modeling the MHTB self-pressurization and spray bar mixing experiments. The tank liquid fill ratio of 50\% was considered. The effect of the accommodation coefficient for calculating the interfacial mass transfer rate during tank self-pressurization on the tank pressure rise was studied first. The study showed that changing the value of the accommodation coefficient from $1.0 \mathrm{e}-3$ to $1.0 \mathrm{e}-1$ had very little effect on the tank pressure when the explicit laminar VOF model was used. The implicit VOF model with the accommodation coefficient varying from $1.0 \mathrm{e}-4$ to $1.0 \mathrm{e}-3$ resulted in similar tank pressures. The results of this model compare well with the experimental data, and with the results of the explicit VOF model with the accommodation coefficient varying between $1.0 \mathrm{e}-3$ and $1.0 \mathrm{e}-1$.

A CFD model for the cooling of cryogenic storage tanks by spraying cold liquid in the vapor region was developed $^{20}$ and applied for modeling the MHTB spray bar mixing experiment with a 50\% liquid fill ratio. The Euler-Lagrange approach implemented in the spray model of the ANSYS Fluent CFD code was utilized for tracking the spray droplets, and for modeling the interaction between the droplets and the continuous phase (ullage). The spray model was coupled with the VOF model via a user subroutine which performs particle tracking in the vapor, removes particles from the vapor domain when they reach the interface, and then adds their contributions to the liquid through source terms. The laminar and turbulent VOF models resulted in very similar tank pressures and interfacial mass transfer rates. This suggests that the effect of turbulence in this case is overpowered by the effect of the forced convection in the tank introduced by the spray. The tank pressure evolutions during the spray period predicted by the two models compare well with the experimental data. A detailed analysis of the tank temperature and flow fields, as well as the droplet temperatures and distribution, showed that the droplets reduce the temperature and promote mixing in the vapor region via heat and mass exchange during spray. The temperature of the droplets increases as they travel in the vapor towards the interface. The passage of the droplets creates a hot region in the area of high droplet concentration in the middle of the vapor phase. The CFD model predicted a very narrow spray angle. There is no information on the spray angle from the experiment to compare with. The temperature evolutions predicted in CFD compare well with the slope of the temperature evolution curves from the experiment. Discrepancies in initial conditions and the position of the spray bar tube relative to the temperature measurement rake between the CFD model and the experiment make the comparison of the fluid temperatures qualitative rather than quantitative. A study of the effect of the accommodation coefficient for calculating the interfacial and droplet mass transfer rates during spray bar mixing in the tank on the tank pressure was conducted. It showed that varying the interfacial accommodation coefficient had very little effect on the tank pressure. Changing the droplet accommodation coefficient had a significant effect on the tank pressure with the value of 2.0e-6 yielding the best comparison with the experiment.

\section{Acknowledgments}

This work was supported by the NASA Space Technology Mission Directorate's Technology Demonstration Missions Program under the Evolvable Cryogenics Project. 


\section{References}

${ }^{1}$ Salzman, J., "Fluid management in space-based systems," Proceedings of the Engineering, Construction, and Operations in Space, 5th international conference on space, Vol. 1, 1996, p. 521-6.

${ }^{2}$ Martin, J.; and Hastings, L.: "Large-Scale Liquid Hydrogen Testing of a Variable Density Multilayer Insulation with a Foam Substrate,” NASA/TM-2001-211089, Marshall Space Flight Center, AL, June 2001.

${ }^{3}$ Hastings, L.J., Flachbart, R.H., Martin, J.J., Hedayat, A., Fazah, M., Lak, T., Nguyen, H., Bailey J.W. "Spray Bar ZeroGravity Vent System for On-Orbit Liquid Hydrogen Storage” NASA TM-212926, 2003.

${ }^{4}$ Barsi, S. and Kassemi, M. "Investigation of Tank Pressurization and Pressure Control-Part II: Numerical Modelling", ASME Journal of Thermal Science \& Engineering Applications, Vol. 5, No 2, pp- 041006: 1-9, December 2013

${ }^{5}$ Kartuzova, O., Kassemi M., "Modeling Interfacial Turbulent Heat Transfer during Ventless Pressurization of a Large Scale Cryogenic Storage Tank in Microgravity," AIAA 47 th Joint Propulsion Conference, AIAA, San Diego, CA, 2011

${ }^{6}$ Grayson, G.D., Lopez, A., Chandler, F.O., Hastings L.J., Tucker, S.P., "Cryogenic Tank Modeling for the Saturn AS-203 Experiment," Proceedings of the 42nd AIAA/ASME/SAE/ASEE Joint Propulsion Conference, AIAA 2006-5258, 2006.

${ }^{7}$ Barsi, S., Kassemi, M., "Numerical and Experimental Comparisons of the Self-Pressurization Behavior of an LH2 Tank in Normal Gravity", Cryogenics, 48(3/4), pp. 122-129, 2007.

${ }^{8}$ Kartuzova, O., Kassemi, M., "Modeling Active Pressure Control in a Large Scale Cryogenic Storage Tank in Normal Gravity," AIAA 48 ${ }^{\text {th }}$ Joint Propulsion Conference, AIAA, Atlanta, GA, 2012

${ }^{9}$ Panzarella, C.H. and Kassemi, M., Comparison of Several Zero-Boil-Off Pressure Control Strategies for Cryogenic Storage in Microgravity, Journal of Power \& Propulsion, Vol. 25, No. 2, pp. 424-434, 2009.

${ }^{9}$ Panzarella, C.H. and Kassemi, M., Pressure Control of Large Cryogenic Tanks in Microgravity, Cryogenics, Vol. 44/6-8, pp. 475-483, 2004.

${ }^{9}$ Panzarella, C.H. and Kassemi, M., On the Validity of Purely Thermodynamic Description of Two-Phase Cryogenic Storage Tank, Journal of Fluid Mechanics, Vol 484, pp.136-148, 2003.

${ }^{12}$ Kumari, N. Bahadur, V., Hode, M., Salamon, T., Kolodner, P, Lyons, A., Garimella, S. V., "Analysis of evaporating mist flow for enhanced convective heat transfer", International Journal of Heat and Mass Transfer 53 (2010) 3346-3356.

${ }^{13}$ Sirignano, W.A., "Fluid Dynamics of Sprays," Journal of Fluids Engineering, Vol. 115, no. 3, pp. 345-378, September 1993.

${ }^{14}$ Crowe, C.T., Sharma, M.P., and Stock, D.E., "The Particle-Source-in Cell (PSI-CELL) Model for Gas-Droplet Flows", J. Fluids Eng., Vol. 99, pp. 325, 1977.

${ }^{15}$ Raju, M.S., and Sirignano, W.A., "Spray Computations in a Centerbody Combustor" Journal of Engineering for Gas Turbines and Power, Vol. 1, No. 4, pp. 710-718, October 1989.

${ }^{16}$ Raju, M.S., "Current Status of the Use of Parallel Computing in Turbulent Reacting Flows, Computations Involving Sprays, Scalar Monte Carlo Probability Density Function \& Unstructured Grids", Advances in Numerical Heat Transfer, Vol. 2, ch. 8, pp.259-287, 2000.

${ }^{17}$ Nguyen, H.: Zero-G "Thermodynamic Venting System (TVS) Performance Prediction Program", Rockwell Aerospace, Contract NAS8-39202, May 24, 1994

${ }^{18}$ Grayson et al, "CFD Modeling of Helium Pressurant Effects on Cryogenic Tank Pressure Rise Rates in Normal Gravity", AIAA 2007-5524, 43rd AIAA/ASME/SAE/ASEE Joint Propulsion Conference \& Exhibit - 11 July 2007, Cincinnati, OH,

${ }^{19}$ Menter, F. R., "Two-Equation Eddy-Viscosity Turbulence Models for Engineering Applications," AIAA Journal, Vol. 32 No. 8, 1994, pp. 1598-1605

${ }^{20}$ Kartuzova, O., Kassemi, M., Agui, J., Moder, J. "Self-Pressurization and Spray Cooling Simulations of the Multipurpose Hydrogen Test Bed (MHTB) Ground-Based Experiment," AIAA 50 th Joint Propulsion Conference, AIAA, Cleveland, OH, 2014

${ }^{21}$ Marek, R., and Straub, J., "Analysis of the evaporation coefficient and the condensation coefficient of water," International Journal of Heat and Mass Transfer, Vol. 44, 2001, pp. 39-53.

${ }^{22}$ Lemmon, E.W., McLinden, M.O., and Friend, D.G., "Thermophysical Properties of Fluid Systems" in NIST Chemistry WebBook, NIST Standard Reference Database Number 69, Eds. Linstrom, P.J., and Mallard, W.G., National Institute of Standards and Technology, Gaithersburg MD, 20899, http://webbook.nist.gov.

${ }^{23}$ Hirt, C.W., and Nichols B.D., "Volume of fluid (VOF) method for the dynamics of free boundaries," Journal of Computational Physics, Vol. 39 No. 1, 1981, pp. 201-225.

${ }^{24}$ Schrage, R.W., A theoretical study of interphase mass transfer, Columbia University Press, New York, 1953.

${ }^{25}$ Brackbill J.U., Kothe, D.B., Zemach, C., "A continuum method for modeling surface tension," J. Comp. Phys. Vol. 100, 1992, pp. 335-354.

${ }^{26}$ Wilcox, D.C., Turbulent Modeling for CFD, DCW Industries, Inc., La Canada, California, 1998

${ }^{27}$ Bradshaw, P., Ferriss, D.H., and Atwell, N.P., "Calculation of Boundary-Layer Development Using the Turbulent Energy Equation," Journal of Fluid Mechanics, Vol. 28, No. 3, 1967, pp. 593-616.

${ }^{28}$ ANSYS Fluent Documentation. Release 16.0. November 2014.

${ }^{29}$ S. Morsi, A. and Alexander, A. J. "An Investigation of Particle Trajectories in Two-Phase Flow Systems," Journal of Fluid Mechanics, Vol. 55, No. 2, 1972, pp. 193-208.

${ }^{30}$ Ranz, W. E. and Marshall, W. R., Jr. "Evaporation from Drops, Part I," Chemical Engineering Progress, Vol. 48, No. 3, 1952, pp. 141-146.

31 Ranz, W. E. and Marshall, W. R., Jr. "Evaporation from Drops, Part II," Chemical Engineering Progress, Vol. 48, No. 4, 1952, pp. 173-180. 


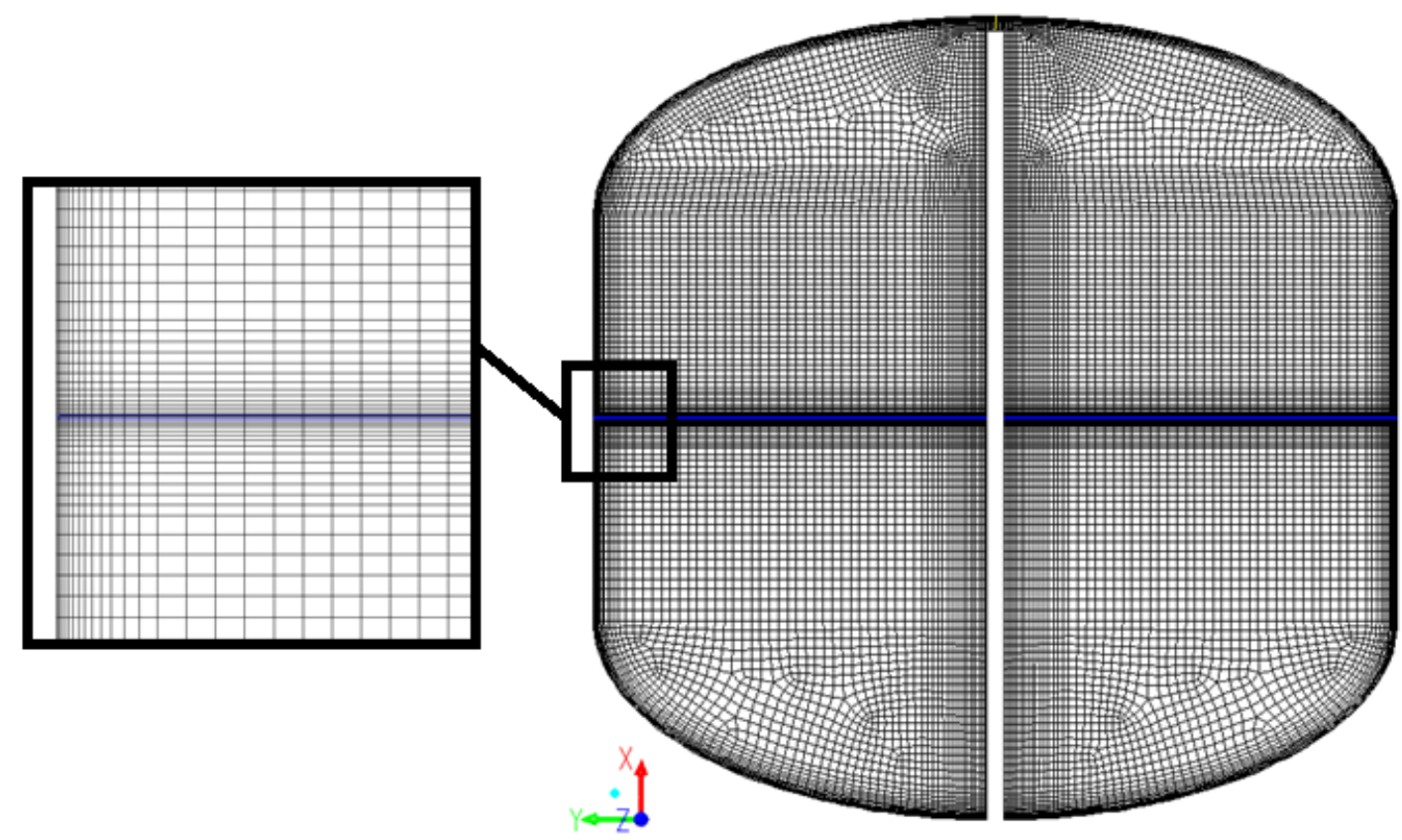

Figure 1: 2D axisymmetric grid used for the $50 \%$ fill ratio self-pressurization cases $(9,246$ cells $)$

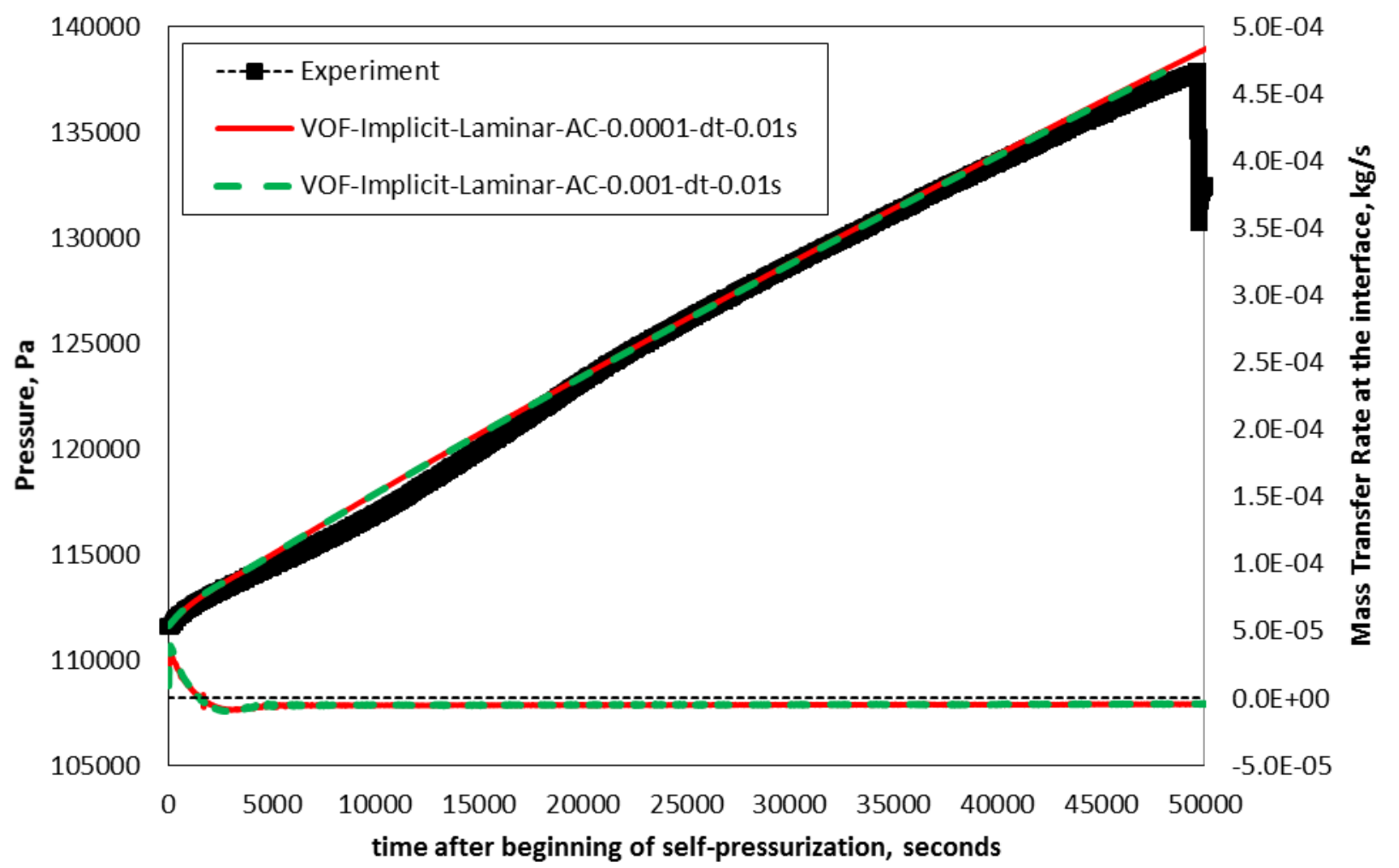

Figure 2a: Effect of the accommodation coefficient during self-pressurization with the implicit VOF model 


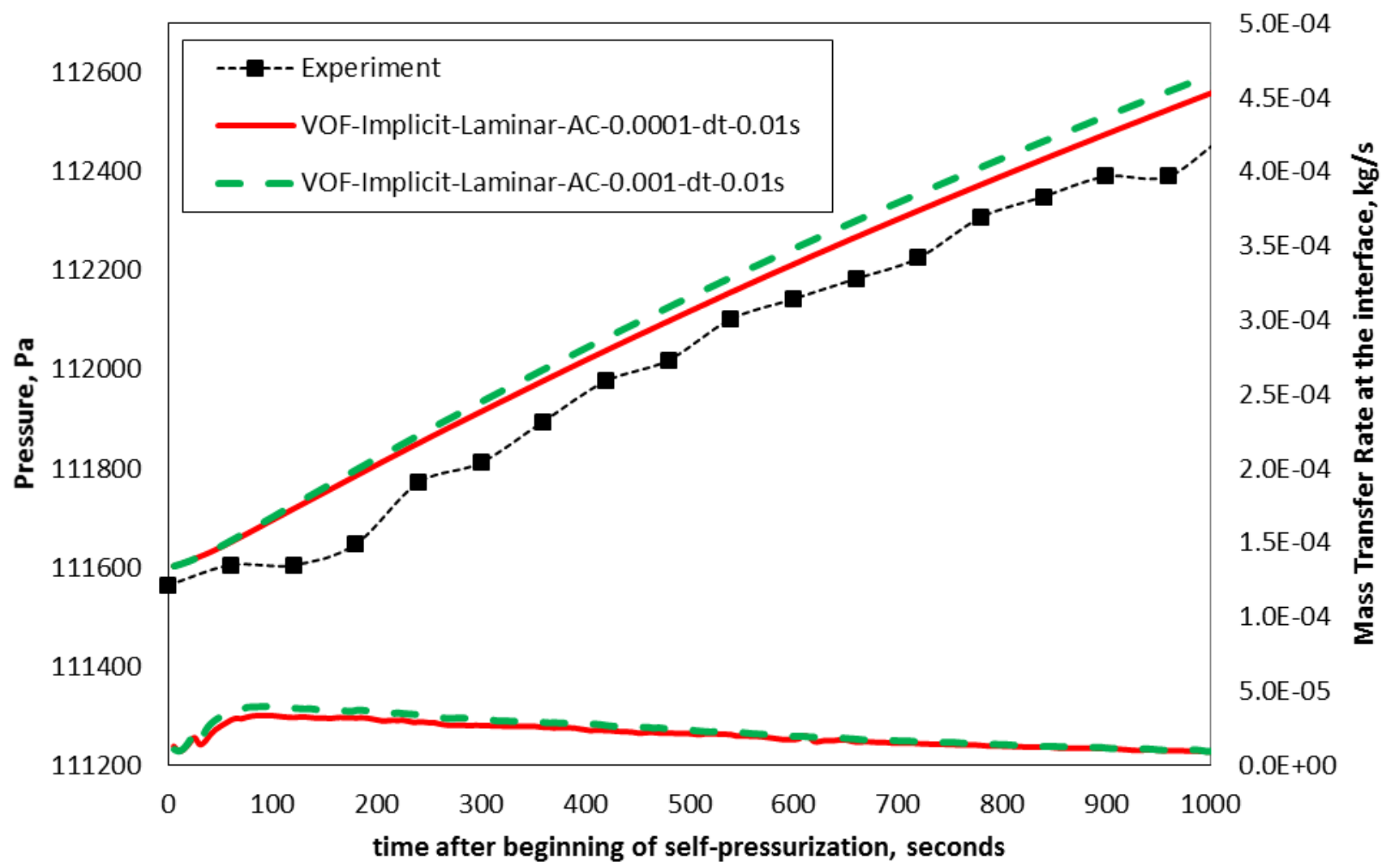

Figure 2b: Effect of the accommodation coefficient during self-pressurization with the implicit VOF model

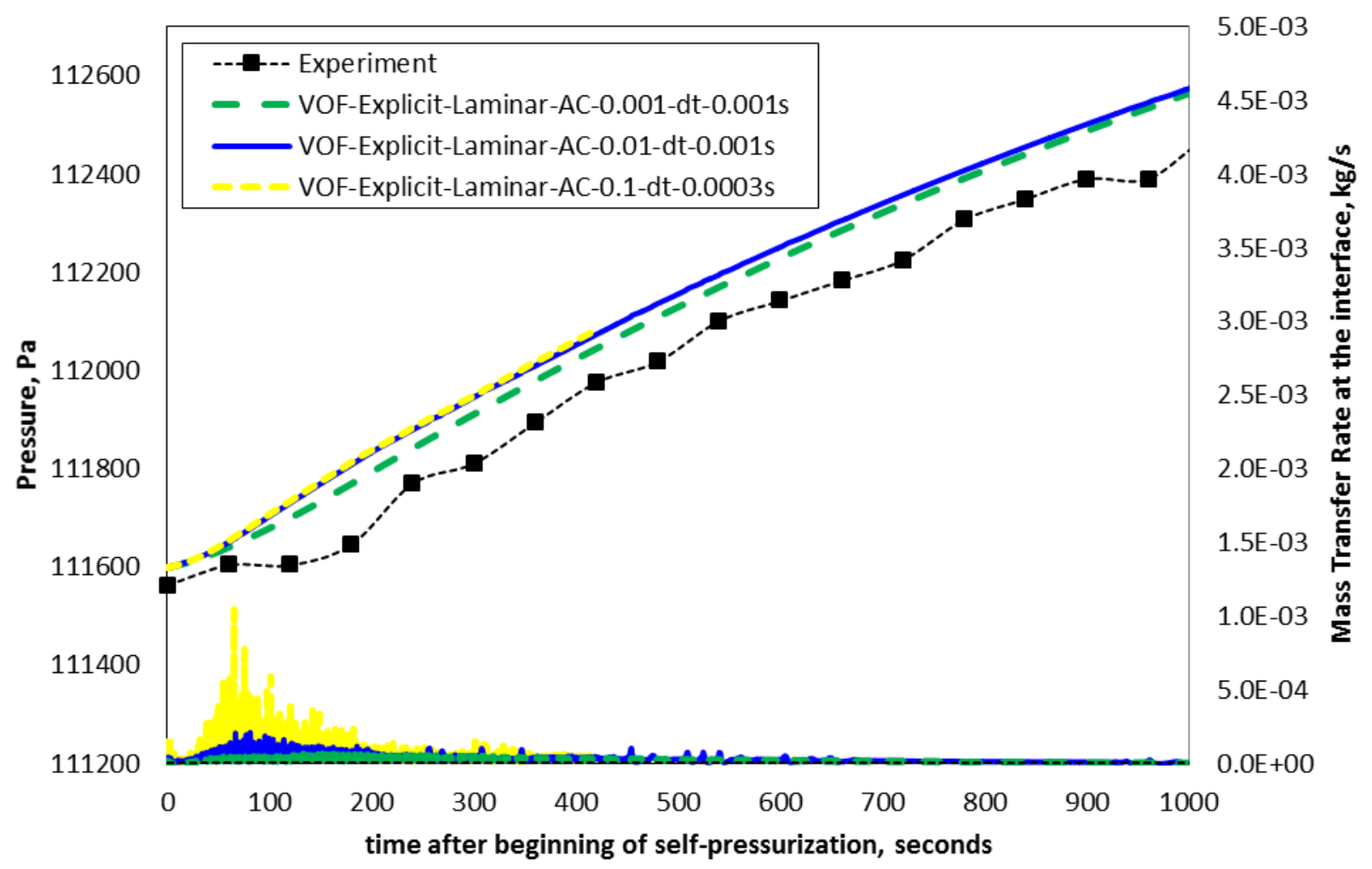

Figure 3: Effect of the accommodation coefficient during self-pressurization with the explicit VOF model 


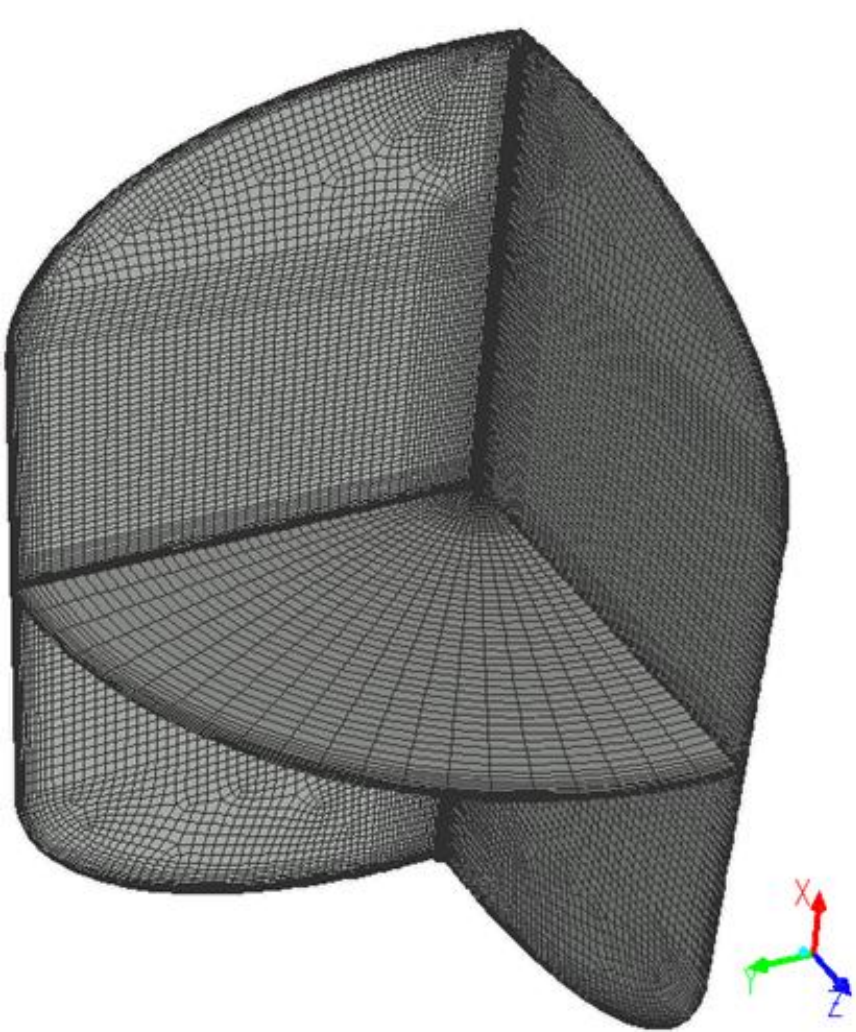

(a)

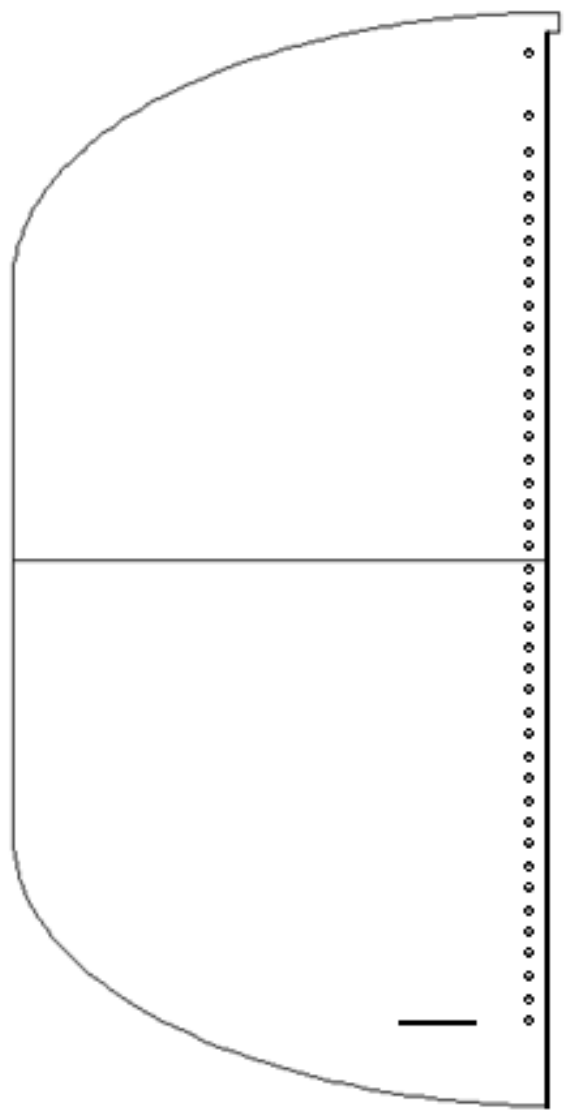

(b)

Figure 4: 3D $90^{\circ}$ sector grid used for the spray bar mixing cases (184,440 cells) (a); and a schematic of spray bar holes and pump locations at the center plane of the injection (b) 


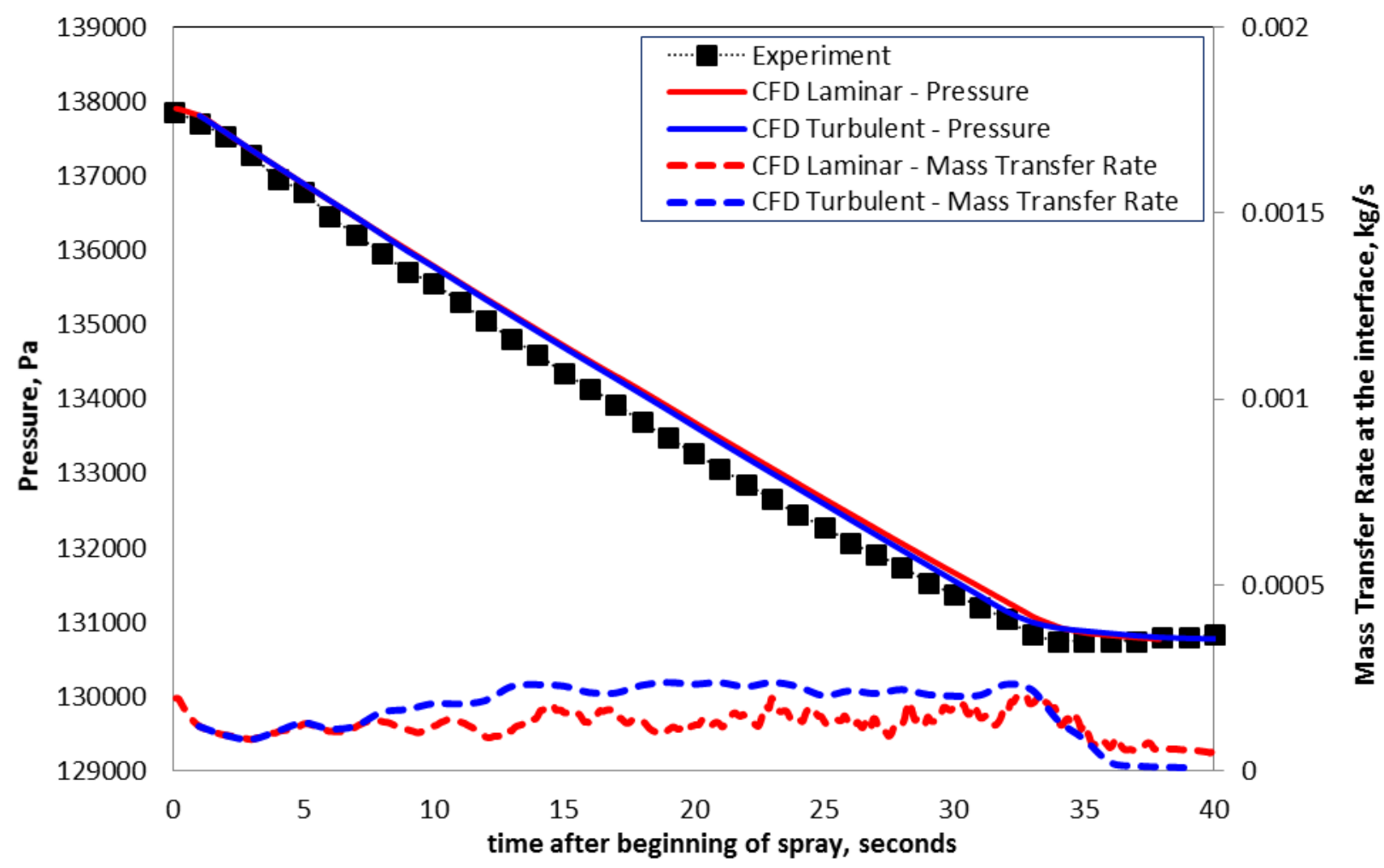

Figure 5: Pressure and interfacial mass transfer rate (positive values represent evaporation) evolutions during spray bar mixing in the MHTB tank - effect of turbulence modeling

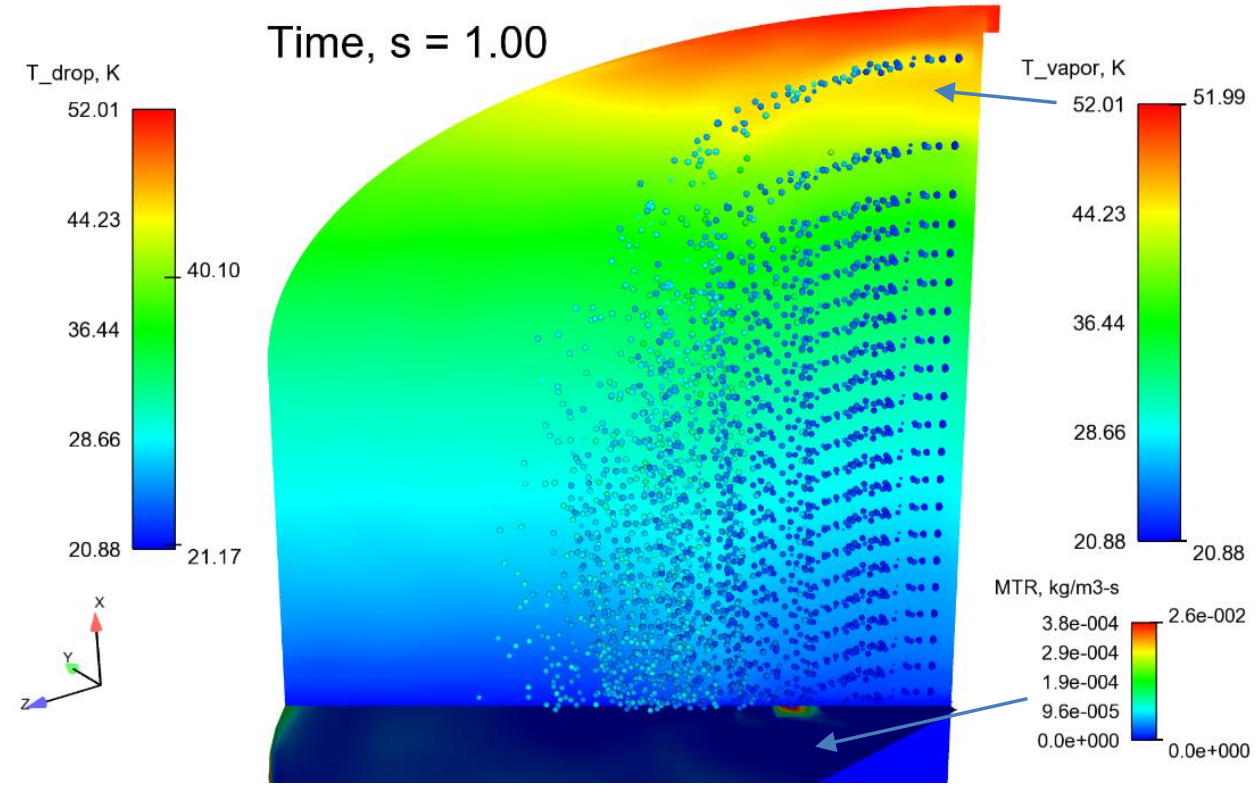

Figure 6: Temperature of the vapor at the center plane of the injection, droplet temperature and mass transfer at the interface after 1 second of spray 

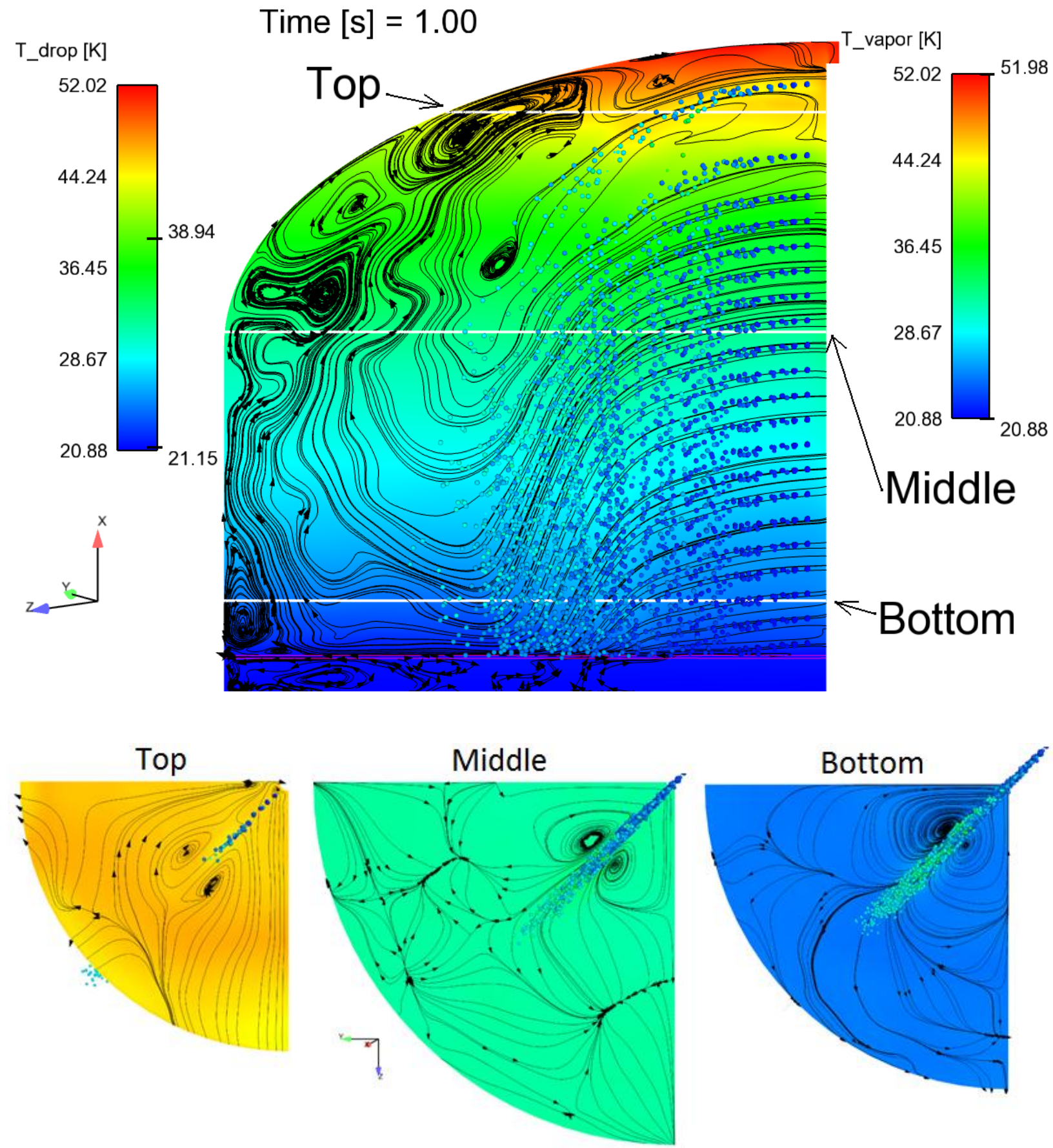

Figure 7: Temperature of the vapor and streamlines at the center plane of the injection and at three horizontal slices; and droplet temperature after 1 second of spray 


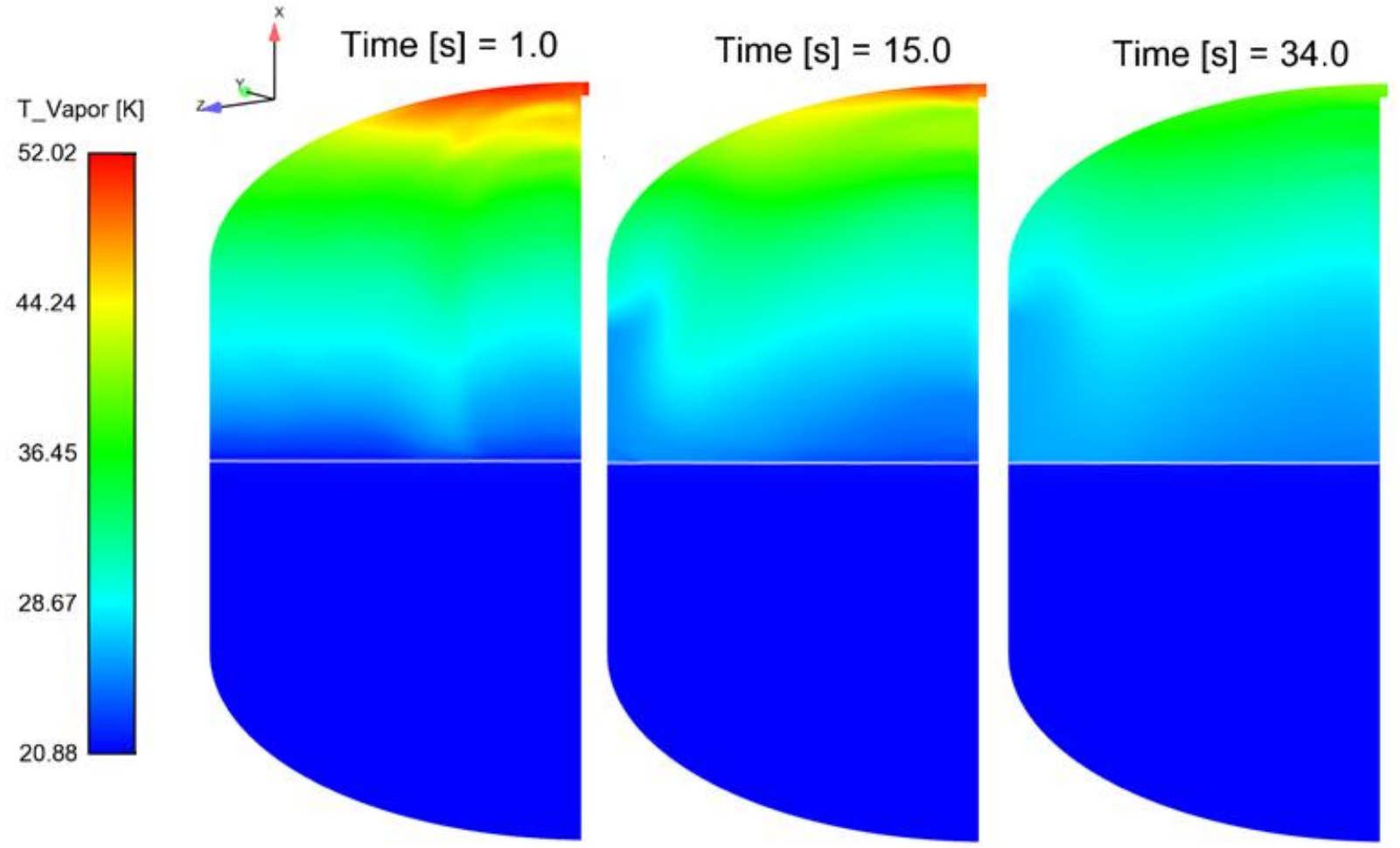

Figure 8: Temperature in the vapor at the center plane of injections at 1;15 and 34 seconds of spray
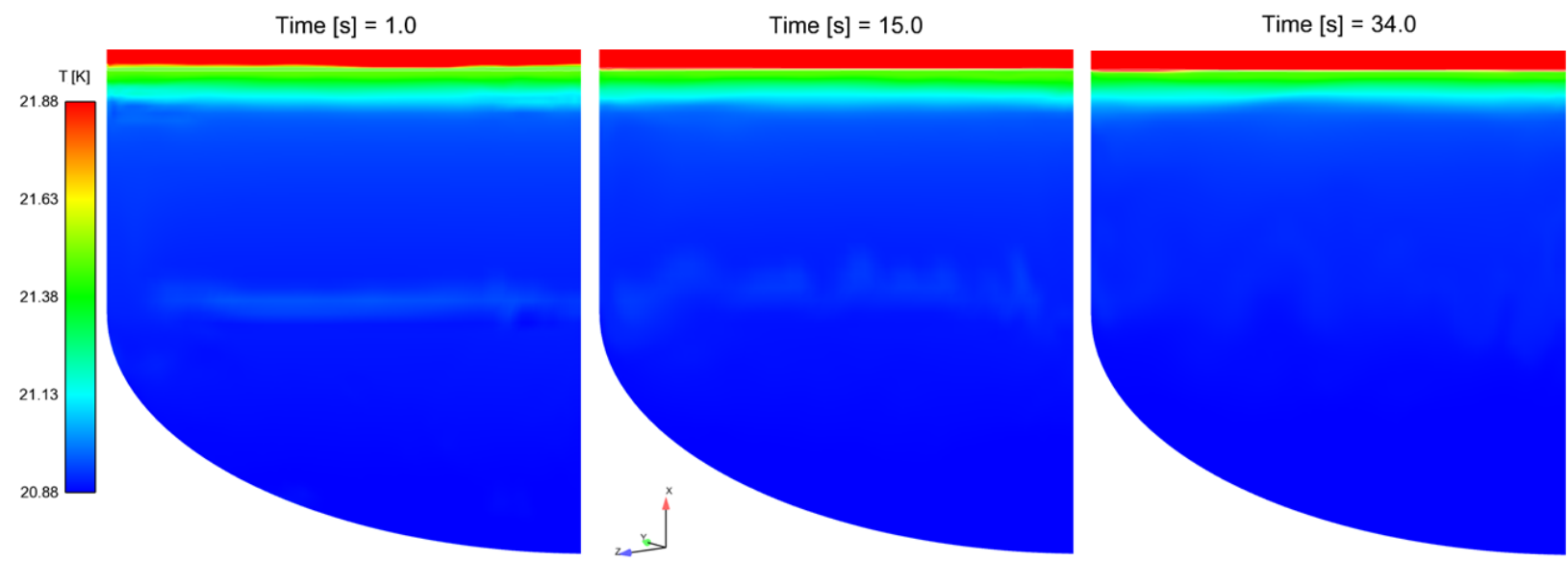

Figure 9: Temperature in the liquid at the center plane of injection at 1;15 and 34 seconds of spray 

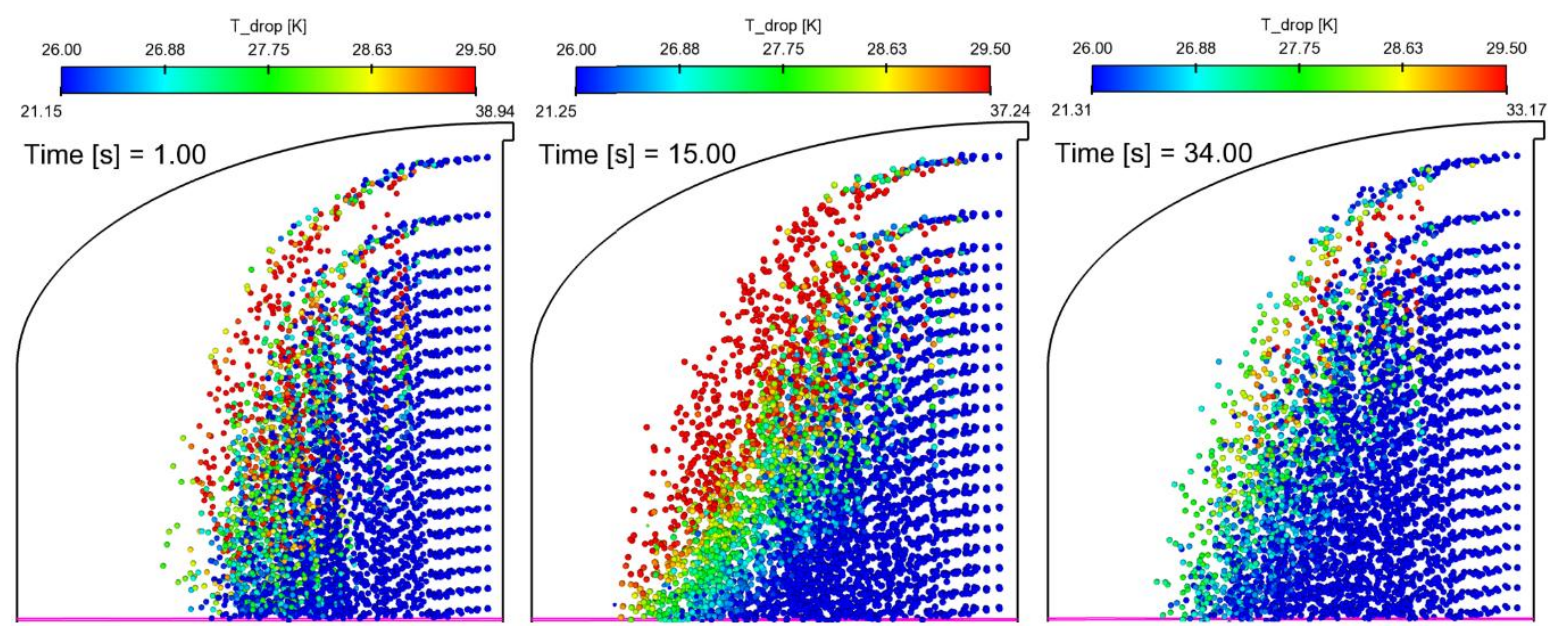

Figure 10: Droplet temperature at the center plane of injection at 1;15 and 34 seconds of spray
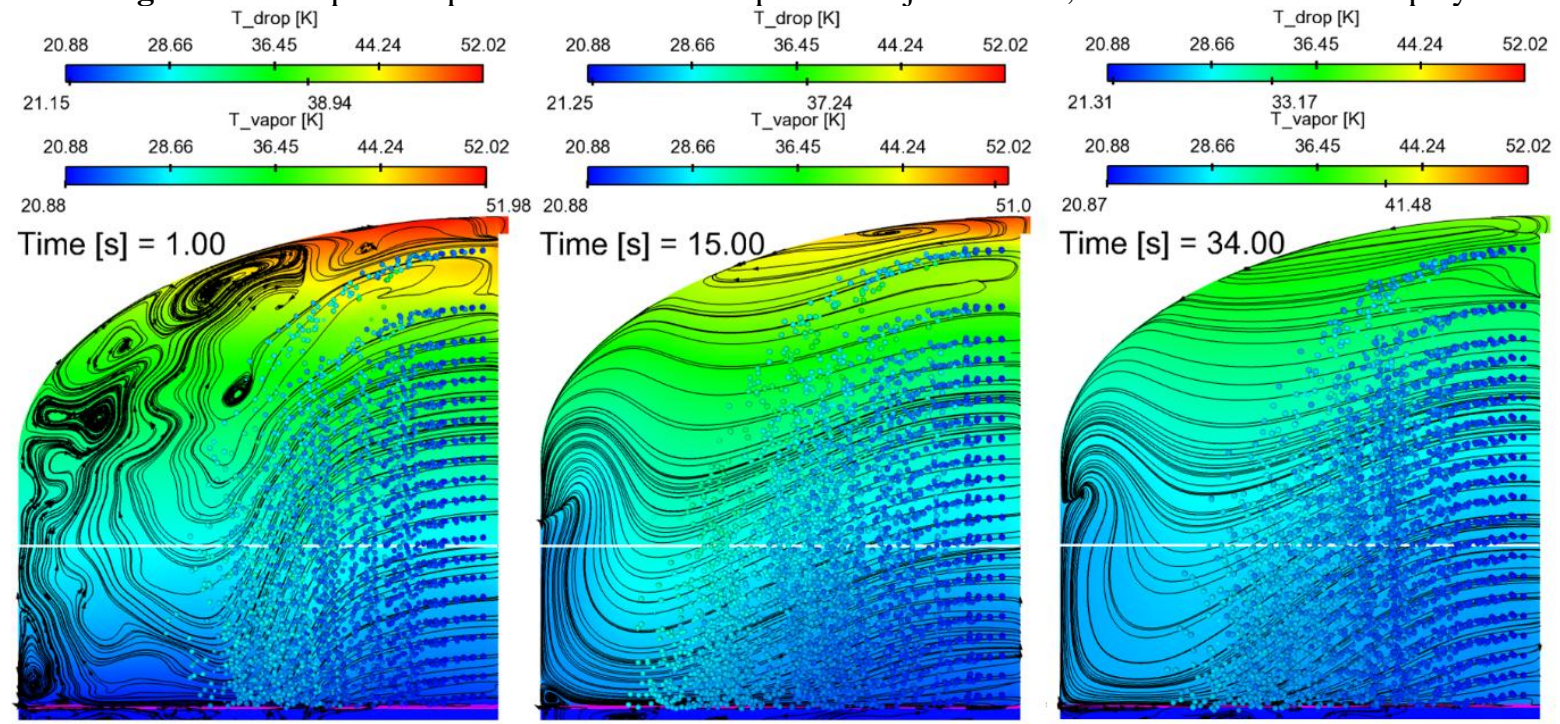

Figure 11: Droplet and vapor temperatures and streamlines at the center plane of injection at 1;15 and 34 seconds
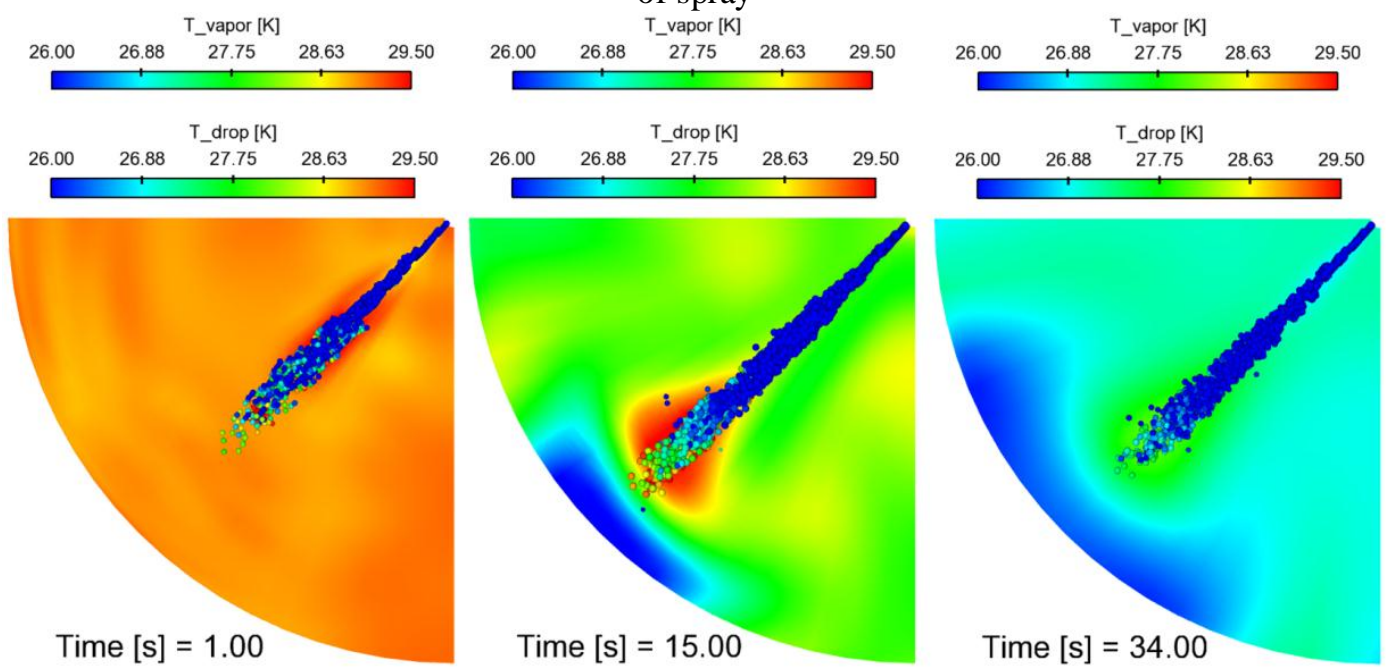

Figure 12: Temperature contours at the horizontal plane in the vapor shown in Fig. 11 (at the temperature measurement location TD4) and droplets colored by the droplet temperature at 1;15 and 34 seconds of spray 


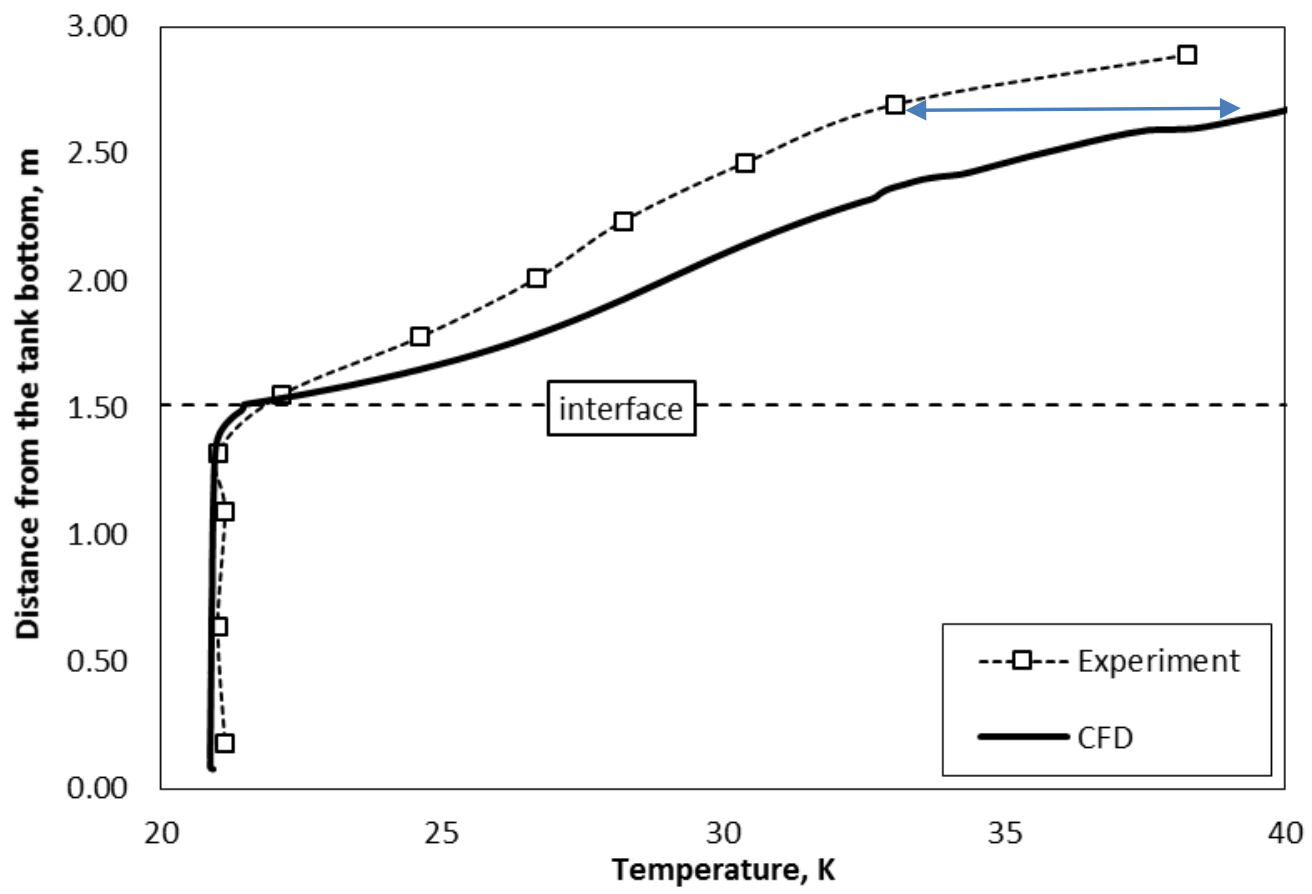

Figure 13: Comparison between experimental and computational temperatures in the tank at the end of selfpressurization (beginning of spray) from the laminar VOF model. Temperatures are plotted along the vertical line (0.74168 $\mathrm{m}$ off the tank centerline)

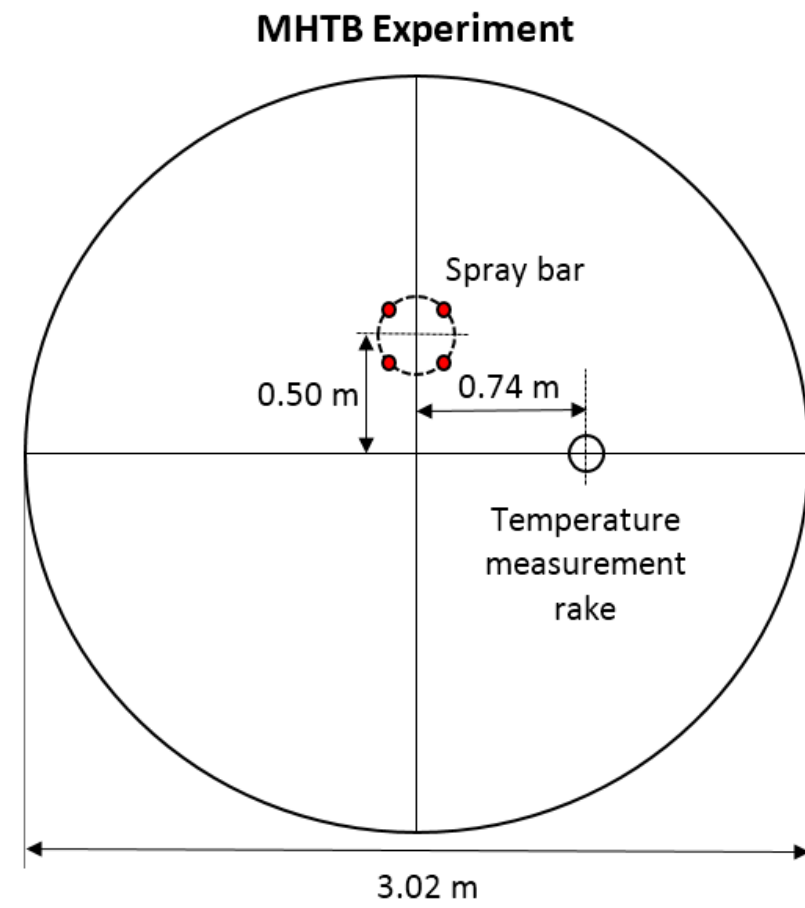

- Approximate orientation of spray bar tubes

(a)

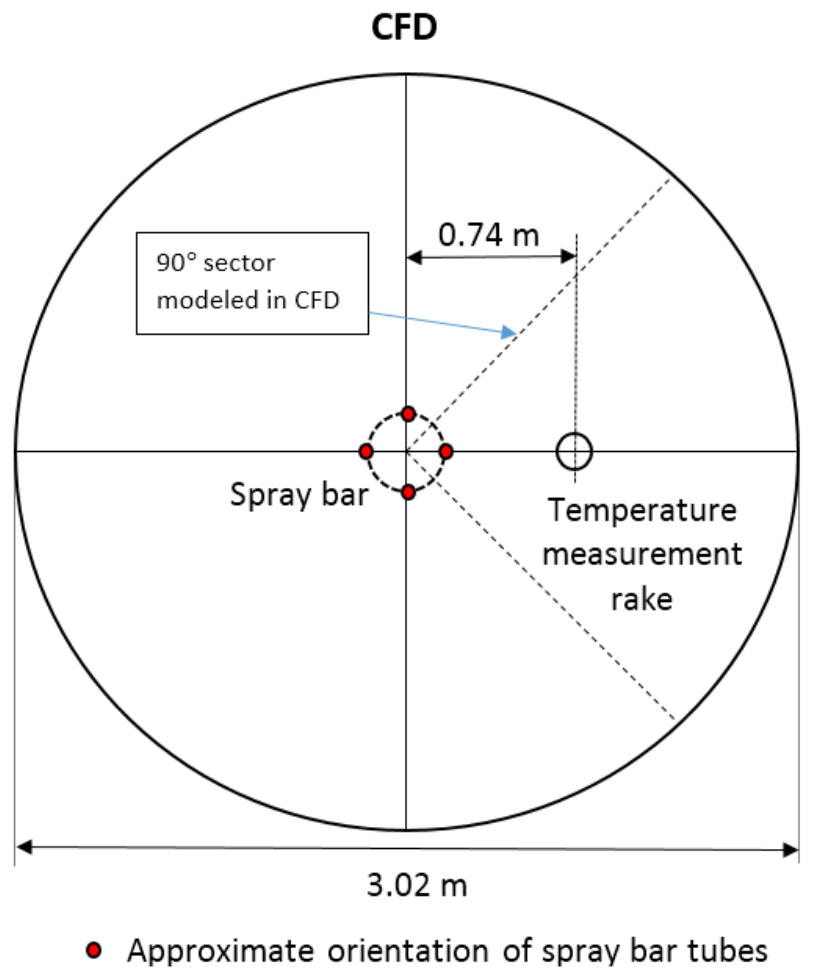

(b)

Figure 14: Schematics of experimental (a) and computational (b) domains and spray bar position and orientation relative to the temperature measurement rake

American Institute of Aeronautics and Astronautics 


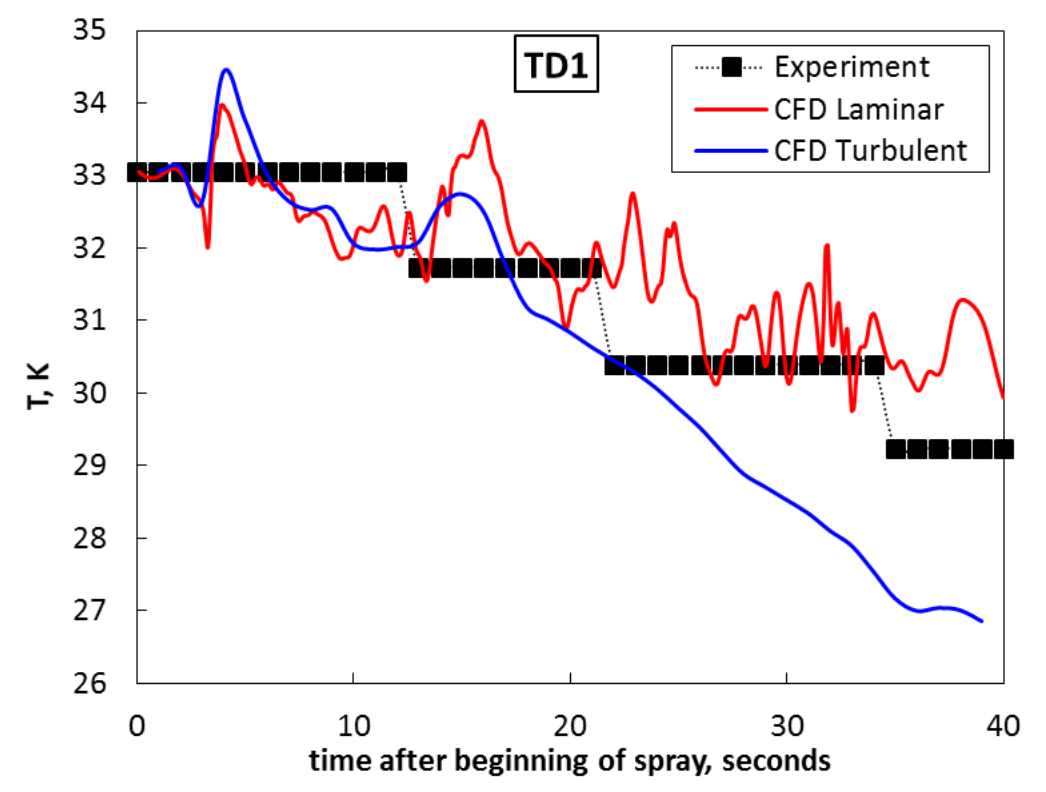

(a)
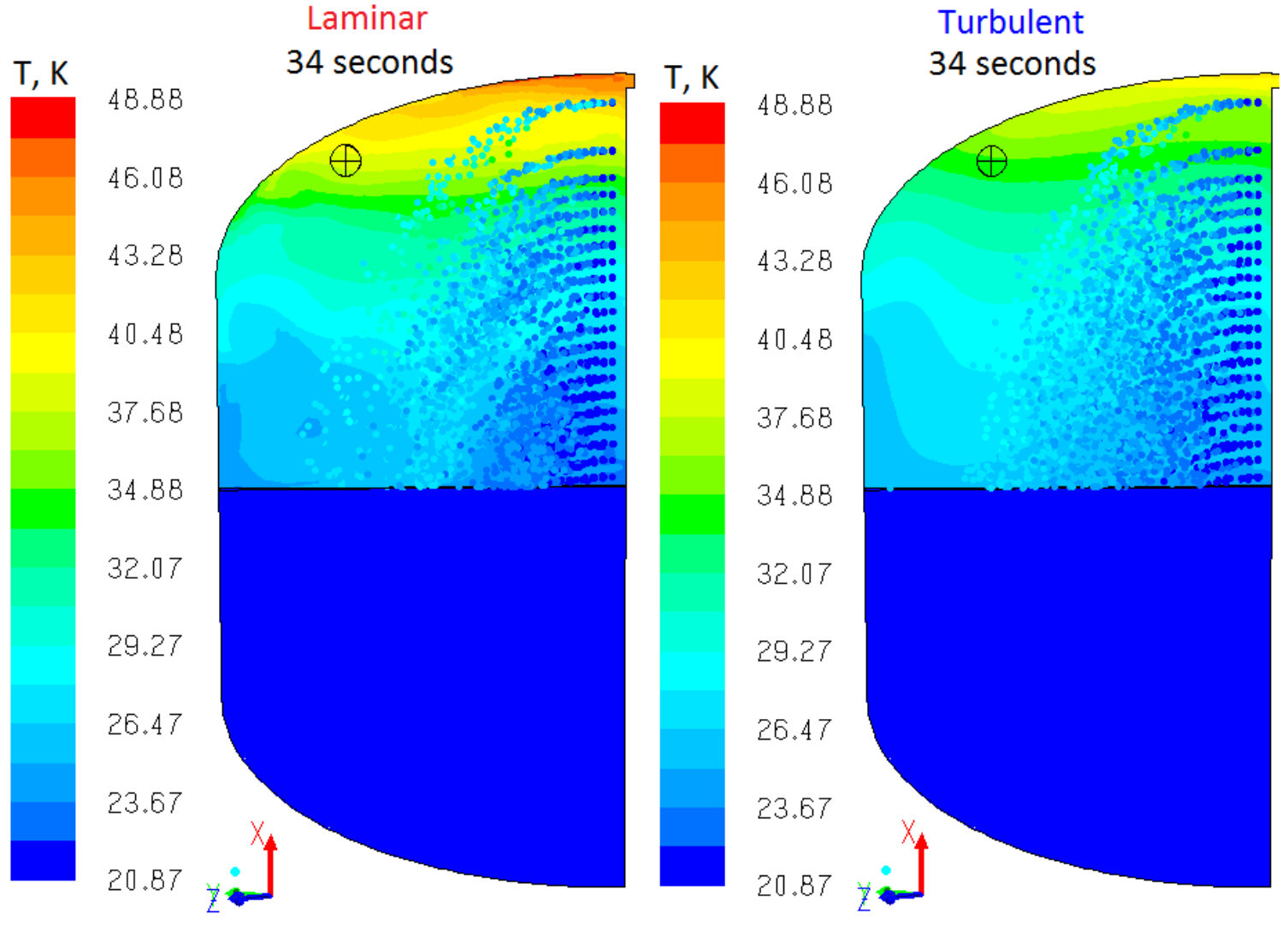

(b)

Figure 15: Temperature evolution for TD1 compared between turbulent and laminar cases and experiment (a); Vapor temperature contours and droplet temperatures at the injection center plane after 34 seconds of spray with TD1 location shown (b) 


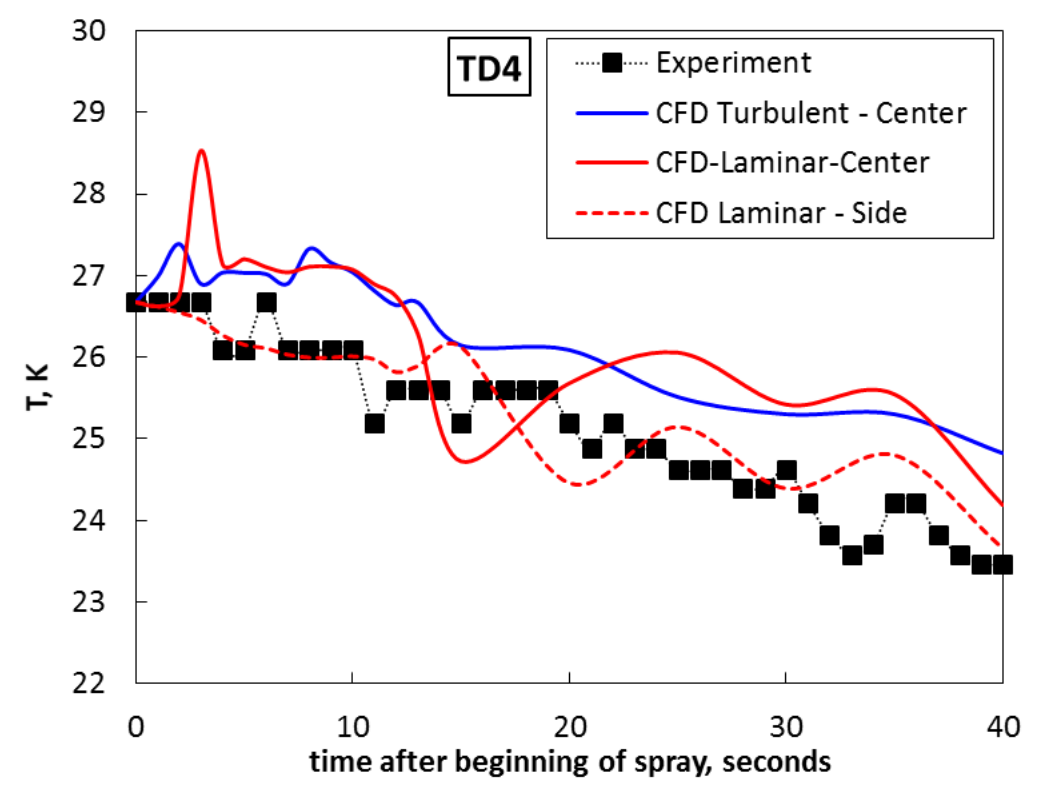

(a)
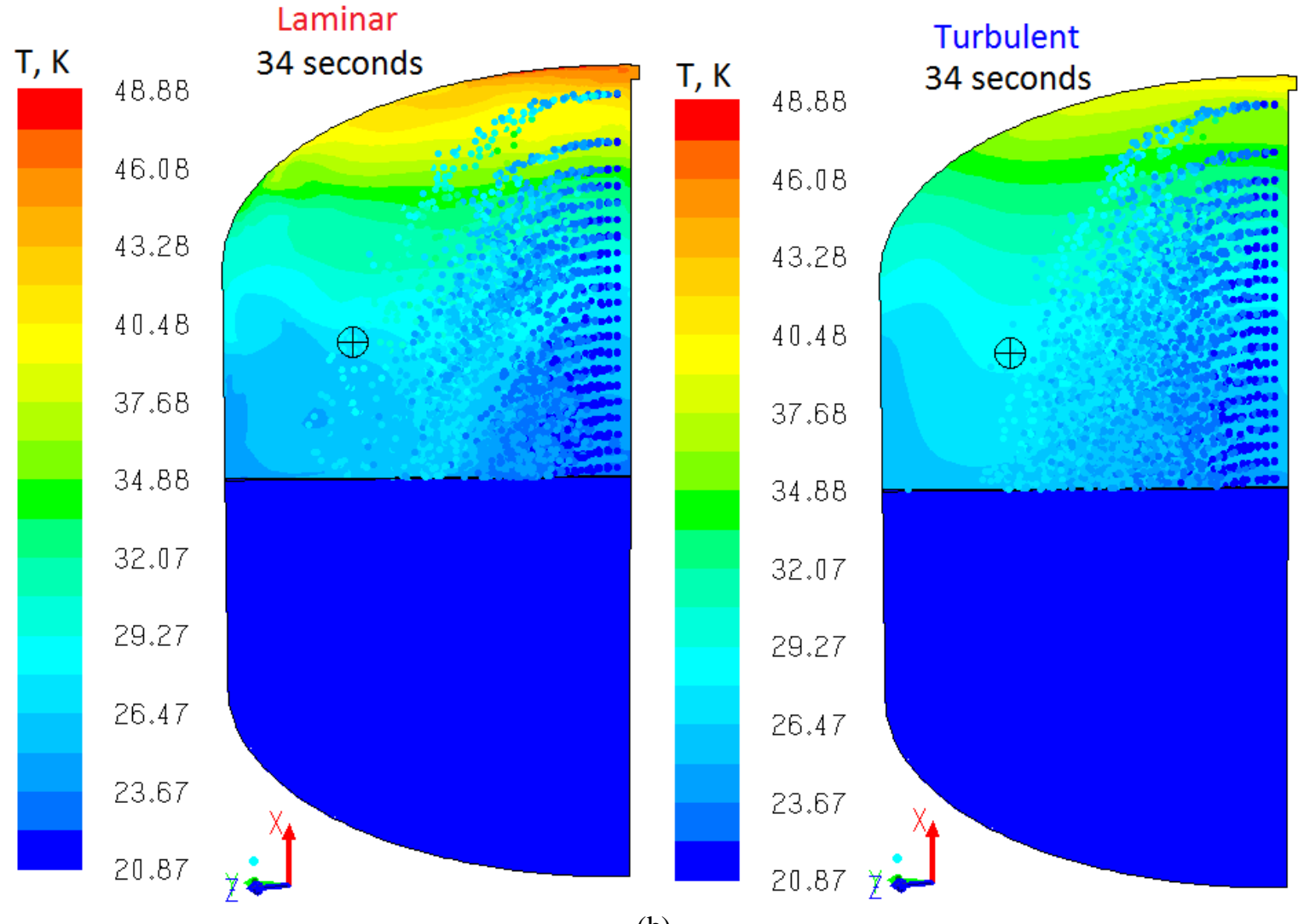

(b)

Figure 16: Temperature evolution for TD4 compared between turbulent and laminar cases and experiment (a); Vapor temperature contours and droplet temperatures at the injection center plane after 34 seconds of spray with TD1 location shown (b) 


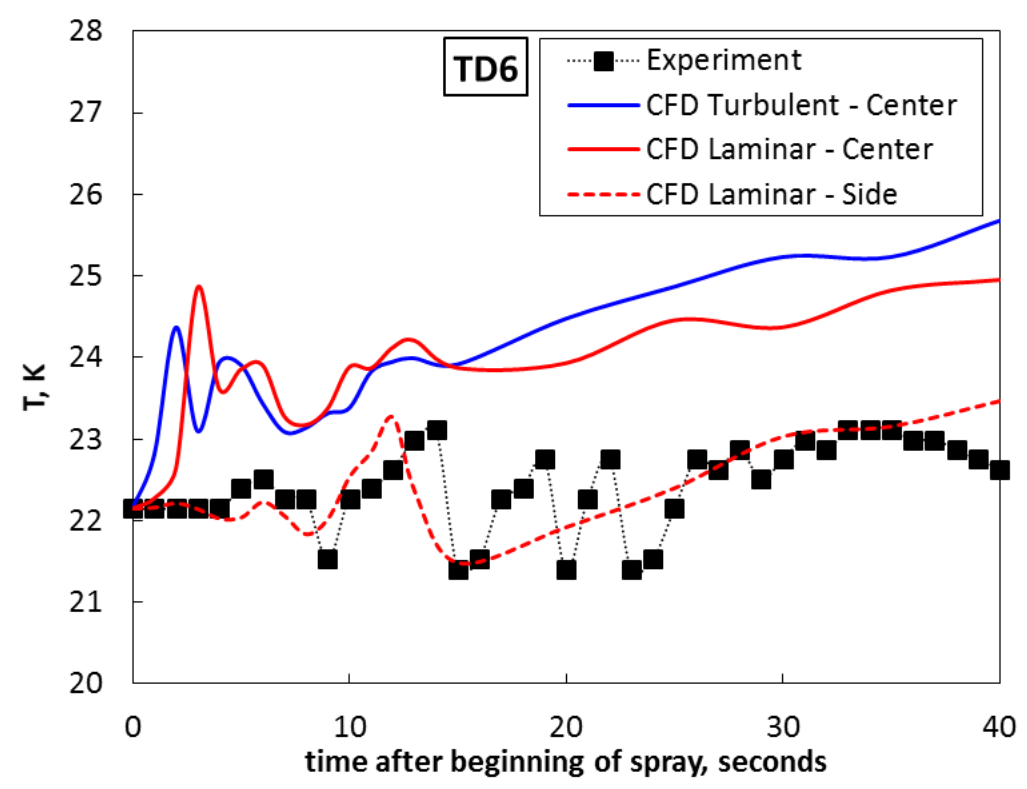

\section{Laminar}

$\mathrm{T}, \mathrm{K}$

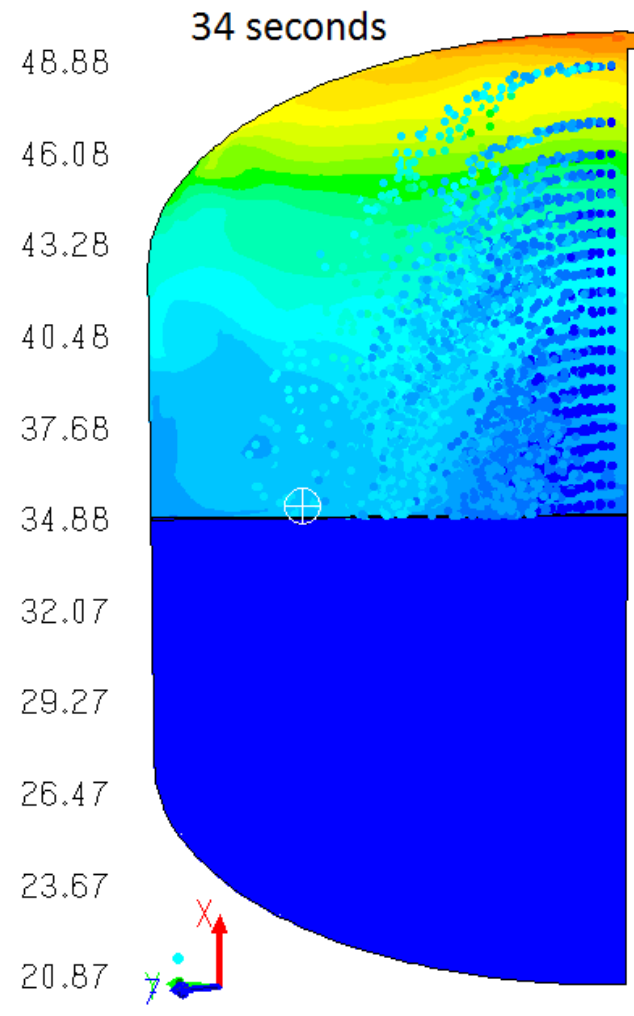

(a)
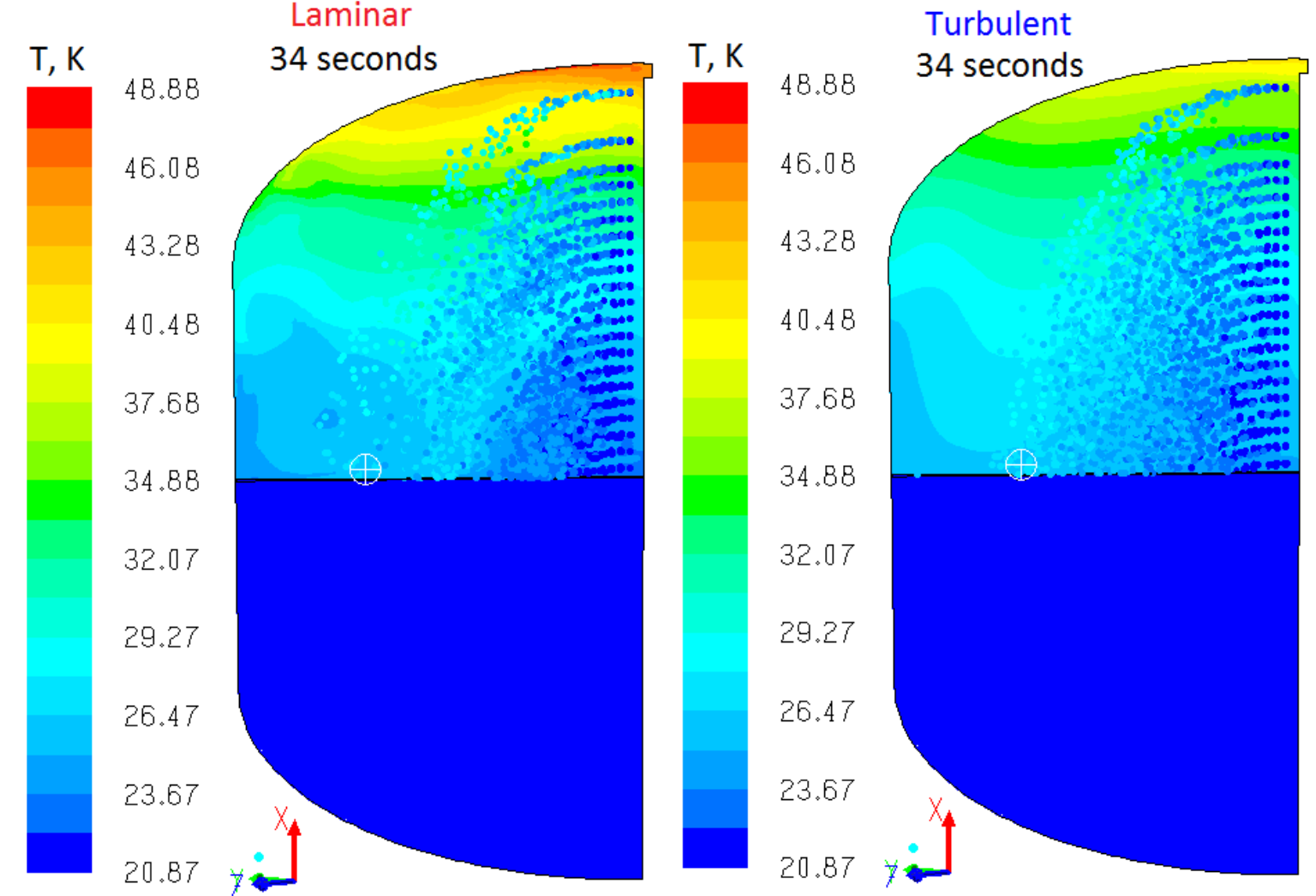

(b)

Figure 17: Temperature evolution for TD6 compared between turbulent and laminar cases and experiment (a); Vapor temperature contours and droplet temperatures at the injection center plane after 34 seconds of spray with TD1 location shown (b) 

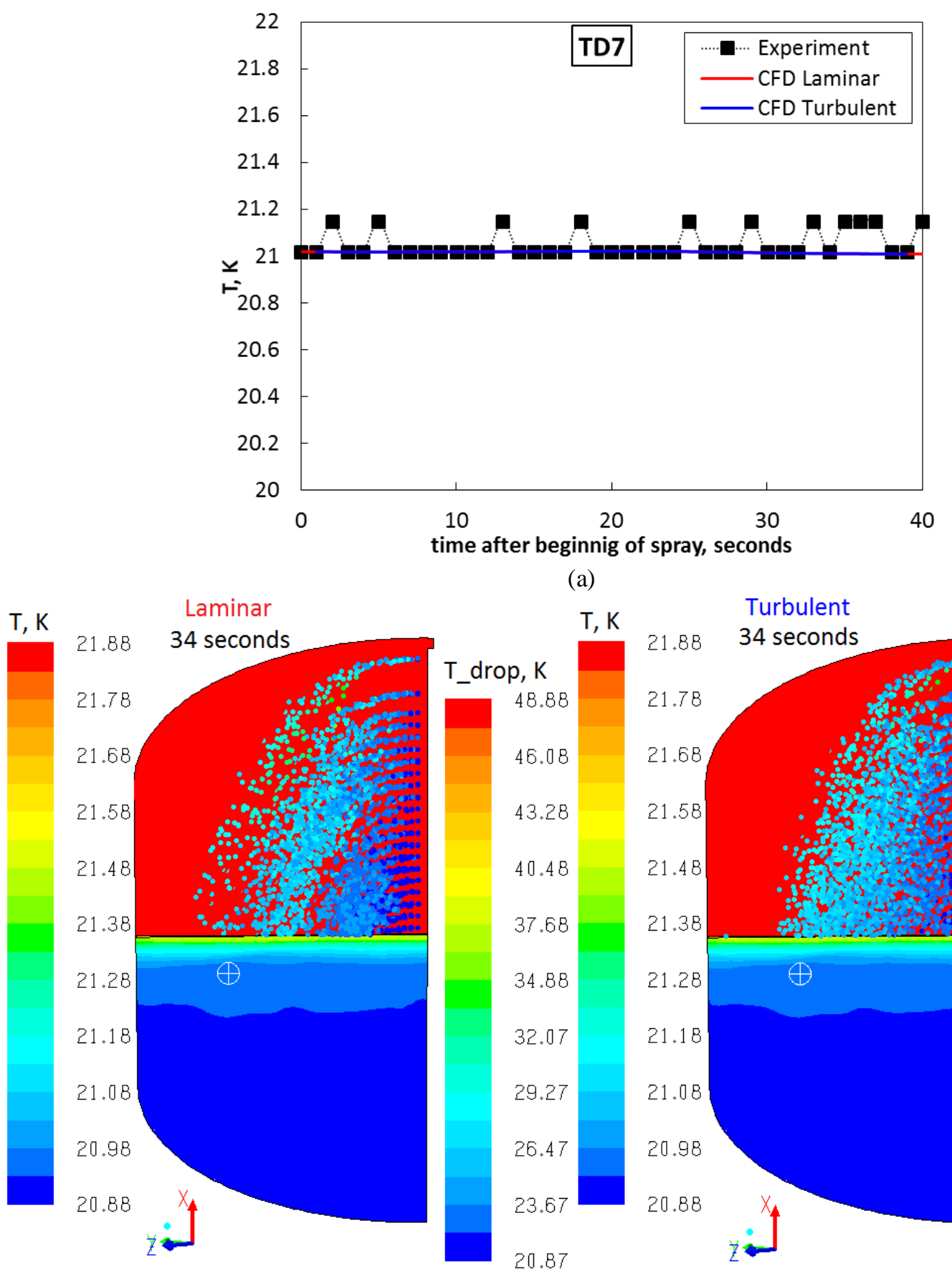

(a)

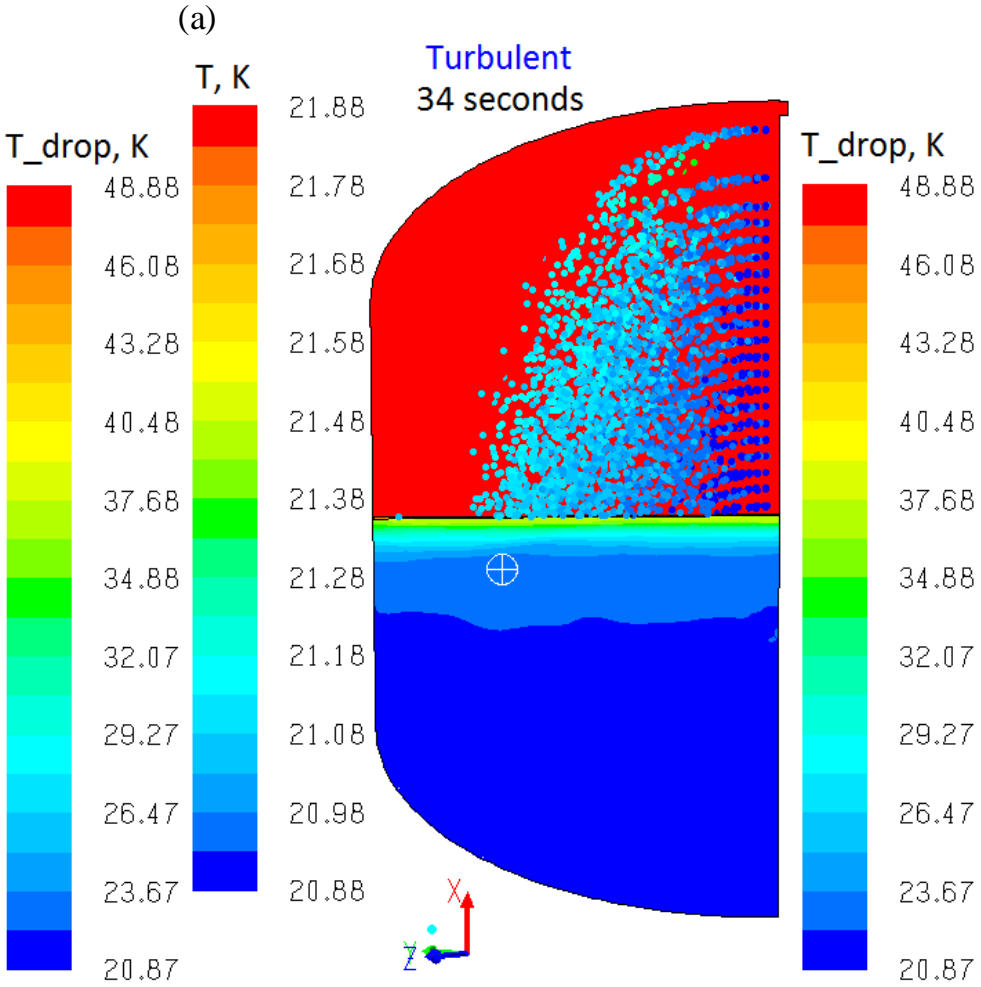

(b)

Figure 18: Temperature evolution for TD7 compared between turbulent and laminar cases and experiment (a); Vapor temperature contours and droplet temperatures at the injection center plane after 34 seconds of spray with TD1 location shown (b) 


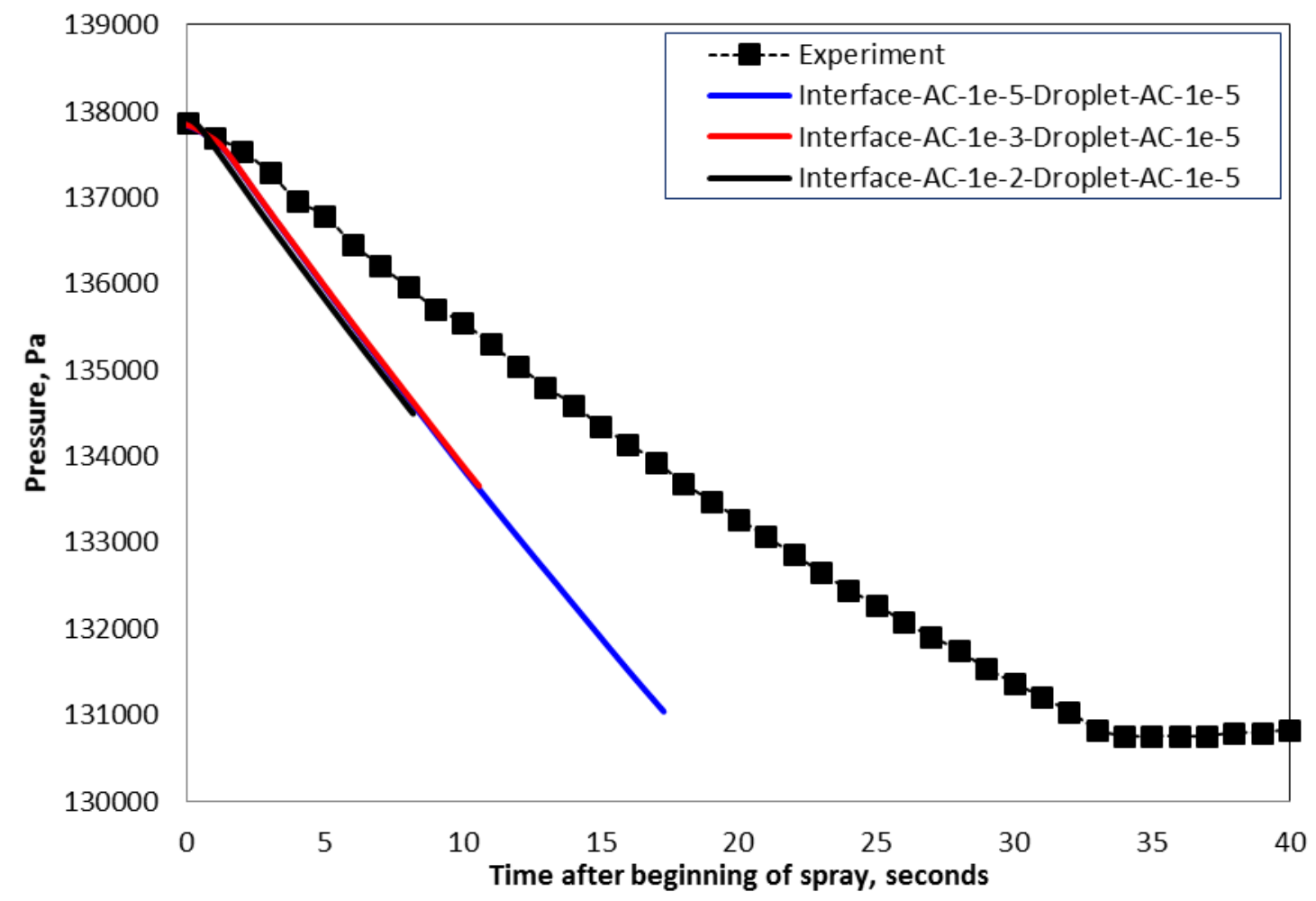

Figure 19: Pressure evolutions in the tank during spray cooling of MHTB tank - effect of the accommodation coefficient at the interface

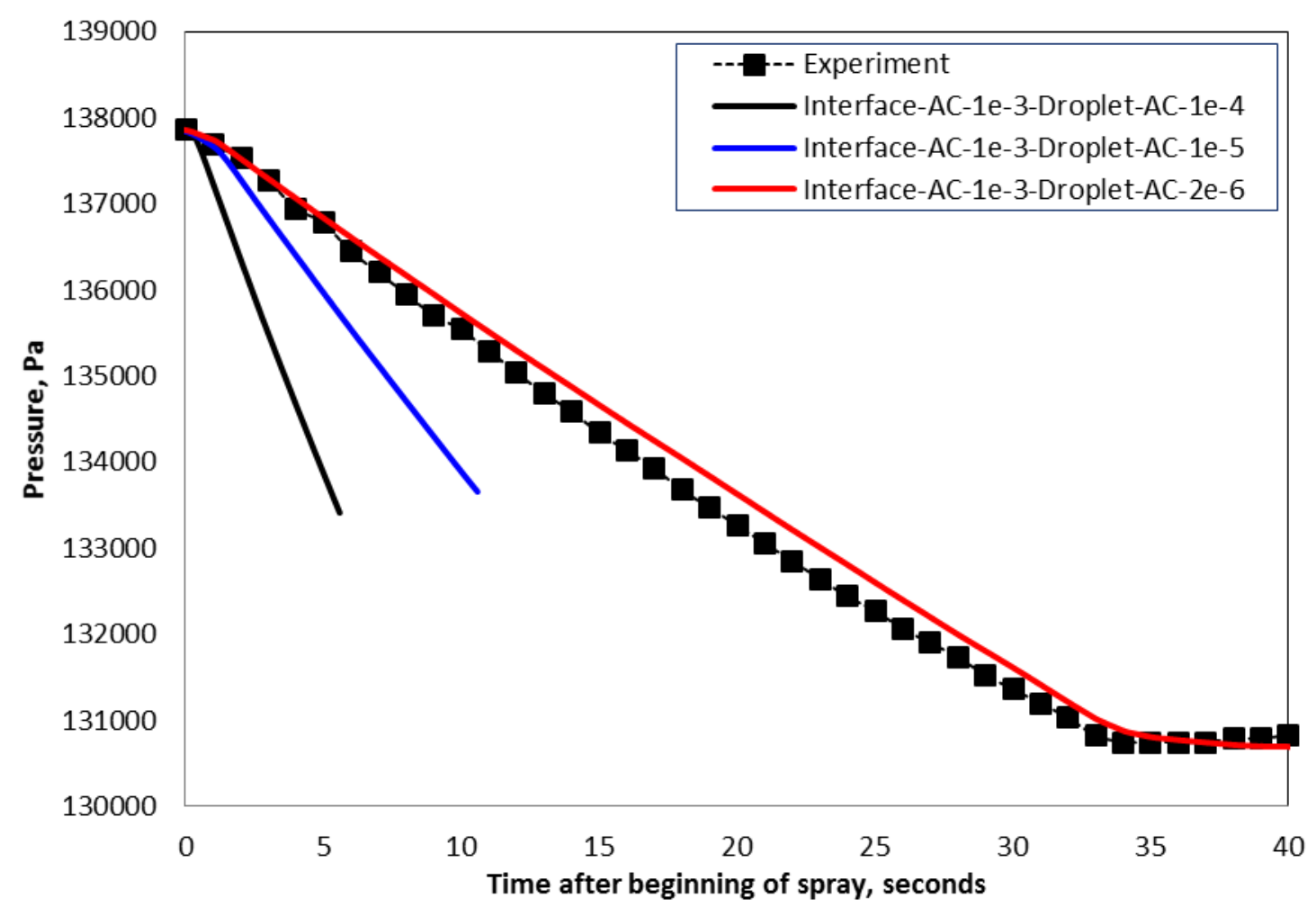

Figure 20: Pressure evolutions in the tank during spray cooling of MHTB tank - effect of the droplet accommodation coefficient 